\title{
Reactions between Neutral Molecules and Cation-radicals in the Gas- phase: Can Protonation Occur without Proton Transfer?
}

\author{
Yury V. Vasil'ev ${ }^{\text {a)* }}$, Douglas F. Barofsky ${ }^{\text {a) }}$, Joseph S. Beckman ${ }^{\text {a) }}$, Benjamin J. Bythell, ${ }^{\text {b)* }}$
}

a) Department of Chemistry, Oregon State University, Corvallis, OR 97331

b) Department of Chemistry and Biochemistry, University of Missouri-St. Louis, St. Louis, MO 63121

Submitted to Int. J. Mass Spectrom. (IJMS-D-15-00066.R1):

14 August, 2015

Submitted to the special issue "focused on biological radicals and cation-radicals in the gas phase, including ion-ion and ion-electron interactions".

\begin{abstract}
Gas-phase collisions of Gly and Ala with free electrons were employed to form positive ions at well determined energies. At elevated molecular vapor pressure, protonated $[\mathrm{Gly}+\mathrm{H}]^{+}$and $[\mathrm{Ala}+\mathrm{H}]^{+}$ions were also observed. The appearance energies of $[\mathrm{Gly}+\mathrm{H}]^{+}$and $[\mathrm{Ala}+\mathrm{H}]^{+}$were both determined as $0.30 \pm 0.14 \mathrm{eV}$ higher than the ionization energies of their $\mathrm{M}^{+\bullet}$ congeners. Quantum chemical calculations predict proton transfer reactions rather than hydrogen atom abstraction reactions as the likely $[\mathrm{M}+\mathrm{H}]^{+}$forming method in our experiment. Microcanonical rate coefficient calculations using B3LYP/6-311++G(2d,p) frequencies and rotational constants, support abstraction of a $\mathrm{C}_{\text {alpha }}$ proton for glycine, whereas the $\mathrm{C}$ terminal proton abstraction mechanism was found as being more favorable for alanine. Additionally, substantial immonium ion formation was observed at experimental energies identical to either the protonated product or cation radical for glycine and alanine, respectively. Theoretical barriers to $\mathbf{M}^{+\bullet}$ cation radical fragmentation to $\mathrm{HRCNH}_{2}{ }^{+}$indicate that they are product-limited and that the glycine barriers are generally larger than those for alanine.
\end{abstract}

Address reprint requests to: *Dr. Yury V. Vasil'ev, Department of Chemistry, Oregon State University, Corvallis, OR 97331. Email: vasilevy@science.oregonstate.edu or Dr. Benjamin J. Bythell, Department of Chemistry and Biochemistry, University of Missouri-St. Louis, St. Louis, MO 63121. Email: bythellb@umsl.edu

Keywords: electron ionization; hydrogen transfer; proton transfer; peptide fragmentation; ion structure; 


\section{Introduction}

Cross-sections for gas-phase ion-molecule collisions have long been recognized as being controlled by Langevin-type long-range interaction potential [1]. Deviations from this behavior for exo- and endothermic reactions have recently been considered at length [2]. Proton/hydrogen exchanges that accompany many ion-molecule collisions are typical examples of these interactions and they are well described in terms of Brønsted and Lewis acid-bases formalism [3]. Since the first observation of methonium ion $\mathrm{CH}_{5}{ }^{+}$by Tal'roze and Ljubimova [4], protonation phenomenon has become a subject of intensive study in mass spectrometry (MS), playing a key role in chemical ionization [3], CI, and many other MS techniques that deal with protonated species. Although widely used in MS, many aspects of proton/hydrogen transfer resulting in the generation of charged species remain not clearly understood. The most challenging issue in this case is a self-protonation reaction occurring between a neutral molecule and its positive cation-radical [5]. The unexpected observation of $[\mathrm{M}+\mathrm{H}]^{+}$protonated species in electron ionization (EI) mass spectra is considered a secondary process $[4,6]$ and thus confounds interpretation of experimental data. The first reports on EI mass spectra of common amino acids [7-9] do not mention registration of protonated species and unlike their ester derivatives [10]. However, despite these early reports, EI spectra in the NIST data base, clearly indicate the formation of protonated ions for some amino acids [11] has occurred. Majer et al. [12] studying electron ionization of Gly tried to explain the observation of $[\mathrm{M}+1]^{+}$ions and other higher masses ions via the complex nature of chemical processes occurring during evaporation at high molecular temperatures $(\mathrm{M}=$ neutral analyte molecule). From this work it is, however, unclear if protonated species can still be formed also under EI conditions at lower molecular temperatures and to what extent. Another question that requires explanation is whether self-protonation processes occur via hydrogen or proton abstraction. Several theoretical questions regarding the fragmentation of amino acids' cation-radicals [13-16] and intramolecular proton transfer in amino acids [17-20] have been examined in the literature. One should note, however, that while mass spectrometrically observed protonated amino acids might be products of intramolecular reactions, these reactions cannot occur in a single amino acid, but rather proceed within their higher mass charged complexes or as an intermolecular particle transfer during two-body collisions between charged and neutral amino acids [5]. Recent energyresolved fragmentation of amino acids' cation-radicals with the determination of ionization (IE) and appearance energies (AE) of molecular cation-radicals and fragmented cations, respectively, have been examined experimentally by mass spectrometry [21-23]. In principle, these studies could, shed light onto these questions. Nonetheless, there is a discrepancy between these and earlier EI mass spectrometry data [6- 
8] as well as between them and the data produced by photoelectron spectroscopy [24-28] and photoionization mass spectrometry [29]. In the present work, the EI of the two simplest amino acids, glycine (Gly) and alanine (Ala), was re-examined as part of developmental work on a custom-made trochoidal electron monochromator orthogonal-extraction time-of-flight [30,31,33] and the behavior was found to differ for between the two. This finding prompted us to investigate the practical details of what

might be occurring. We have utilized quantum chemical calculations at different levels of theory to aid interpretation of the experimental data.

\section{Methods}

\section{Experimental Details}

A custom-made orthogonal-extraction time-of-flight (oTOF)-MS [30,31] incorporating a trochoidal electron monochromator (TEM) [32] for the generation of an electron beam with an energy spread of 70$200 \mathrm{meV}$ was utilized to produce cation-radicals of Gly and Ala over the 0-75 eV electron energy range. The instrument can handle three-dimensional mass spectra (ion intensity, ion $\mathrm{m} / \mathrm{z}$, electron energy) in real time at a very fast rate $[31,32]$ and thereby allows use of a newly-designed custom-made Direct Exposure Probe (DEP). Gly and Ala samples in aqueous and water/methanol solutions were deposited onto the surface of the direct exposure probe's heating spiral (Fig. 1) and dried prior to inserting the probe into the instrument's ionization chamber. For the external calibration, Ar and air were introduced into the ionization chamber to calibrate the mass-to-charge, $\mathrm{m} / \mathrm{z}$, and calibrate and control linearity of the electron energy scale. In the experiments, where ionization efficiency curves were recorded, only Ar was present and air was shut off. In some experiments, methanol, when it was not completely vaporized from the DEP, served as an additional calibrant. Electron energy resolution was ca. 100-150 meV. In contrast to previous work on peptides [34] where the probe was heated by radiation from the surrounding, hot ionization chamber, in the present work a tungsten coil (2 turns) of the DEP was resistively heated to $100-150{ }^{\circ} \mathrm{C}$ within less than $\sim 0.5$ seconds to vaporize the intact amino acids generating a high vapor density to secure collisions within the vapor. Temperature of the DEP' wire was calibrated in a separate experiment with a thermocouple connected to the DEP. Close distance of the DEP to the electron beam allowed production of sufficient vapor pressure for recording mass spectra even without heating the DEP (it was not sufficient for recording high quality ionization efficiency curves though). To have a stable ion signal, the ionization efficiency curves for Gly and Ala were recorded at the DEP temperature ca. $100-120^{\circ} \mathrm{C}$. In earlier mass spectrometry publications [7, 10], it was also noted that placing solid amino acid directly to the ionization chamber 
provided adequate sample pressure at lower temperatures than in the case of externally heated inlet systems.

In a similar manner to earlier experiments [34], the position of the DEP relative to the electron beam was critical as ion signal and thus mass spectra were only generated when the probe was proximate to rather than physically in the electron beam. By varying the distance between the DEP's tip and electron beam, and the electron energy it was possible to control ion production to yield either molecular cationradicals almost exclusively or simultaneously with their protonated congeners. The separation between probe tip and electron beam insured that cation-radicals of the amino acids studied were only formed by EI, as demonstrated by the energy dependencies of the ion production processes observed in both positive and negative ion modes. Mass spectra recorded with the DEP under conditions favoring molecular cationradicals formation were indistinguishable from those obtained with a conventional direct insertion probe [11] previously. Control experiments performed with the electron beam turned off resulted in no protonated species being detected indicating that protonation likely occurred via processes associated with EI either via collision of the amino acid cation-radicals with their neutral counterparts or via electron ionization of neutral amino acid aggregates. To be certain that positive ions were not formed by pyrolysis, additional experiments were performed with the trochoidal electron monochromator's filament turned off; the result of which was that the ion signals disappeared immediately, thus confirming that sample heating did not produce ions by some pyrolytic action.

\section{Calculation Details}

Standard ab initio and density functional theory (DFT) calculations were performed with the Gaussian 09 suite of programs [35]. Electronic and geometrical structures of intact neutral and positivelycharged Gly and Ala, and the associated transition structures were examined using the B3LYP [36] and M06-2X [37] models utilizing the 6-311++G(2d,p) basis set. Single point energies were then calculated from the B3LYP/6-311++G(2d,p) minima at the MP2/6-311++G(2d,p) [38] level of theory. The MP2 and B3LYP values were then averaged (B3LYP-MP2) to cancel out known errors in the methods [39]. The spinunrestricted formalism (UB3LYP, UM06-2X and UMP2) was used for all calculations of radical systems. Stationary points were characterized by harmonic frequency calculations to identify local energy minima (all real frequencies) and first-order saddle points (transition structures, one imaginary frequency). Multiple transition structures (TSs) were investigated for both the hydrogen transfer and proton transfer mechanisms considered here. Intrinsic reaction coordinate (IRC) calculations were run for all barriers to determine which 
minima the TSs connected and thus define the detailed reaction pathway. The final structures on both the product and reactant sides of the IRC were then optimized with small incremental steps (by utilizing the Gaussian09 keywords IOp(2/9=11,1/8=2)).

MP2/aug-cc-pvdz calculations were also performed on the Gly and Ala neutrals and putative cationradicals. The main purpose of these calculations was to choose the most stable isomer for Gly and Ala cation-radicals. The difference between total zero-point energies of neutral molecules and cation-radicals, both taken with full optimization of energy, determined theoretical adiabatic ionization energy (IE). Comparison between these theoretical values with the present experimental adiabatic IEs helped to choose the most stable isomer of cation-radicals.

\section{Reaction Rate Coefficient Calculations}

Microcanonical rate coefficients for unimolecular decomposition of Glu and Ala dimers (cationradical plus neutral molecule) into protonated amino acids and neutral fragments were calculated utilizing data from the UB3LYP frequency calculations. Frequencies of the TS and the global minimum dimer were used to calculate (Beyer-Swinehart direct count method [40] was applied) the sum of states and density of states, respectively. As activation energy, either energy of TSs in the case of "transition state limited reaction" or energy of the reaction' separated products in the case of "product-limited reactions" were employed (as an upper-bound estimate of the reaction coefficients)."

\section{Results and Discussion}

\section{(1) Experimental Results}

EI mass spectra of Gly and Ala (Figs. 2 and 3) were obtained by ramping the electron energy over 0$25 \mathrm{eV}$ and by variation of the temperature and position of the direct insertion probe by varying the distance between electron beam and the probe's tip. Subsequent increase of the electron energy to $75 \mathrm{eV}$ (mass spectra are not shown) did not lead to any major difference to those spectra recorded with $25 \mathrm{eV}$ electron energy. The ionization efficiency curves of molecular cation-radicals, $\left[\mathrm{M}^{+\bullet}\right]$, as a function of electron energy were recorded (Figs. 4 and 5) and treated with a non-linear Marquardt-Levenberg algorithm fitting technique $[41,42]$ to determine adiabatic IEs. The glycine cation-radical, [Gly ${ }^{+\bullet}$, was estimated to have an appearance energy, $\mathrm{AE}$, of $9.10 \pm 0.10 \mathrm{eV}$, and the alanine cation-radical, [Ala ${ }^{+\bullet}$ ], $8.90 \pm 0.10 \mathrm{eV}$. Previously, vertical electron IEs of Gly were measured by photoelectron spectroscopy as $10.0 \mathrm{eV}$ [24, 25], 9.9 [28], while adiabatic IEs were determined by photoelectron spectroscopy as 9.00 $\pm 0.05 \mathrm{eV}$ [26] (taken 
from [9]), $8.8 \mathrm{eV}$ [24] and by EI mass spectrometry as 9.5 $\pm 0.2 \mathrm{eV}$ [7], 9.25 $\pm 0.10 \mathrm{eV}$ [8], 9.21 $\pm 0.05 \mathrm{eV}$ [9], $8.1 \pm 0.1 \mathrm{eV}$ [22]. Vertical IEs of Ala according to photoelectron spectroscopy are $9.8 \mathrm{eV}$ [24], $9.85 \mathrm{eV}$ [25], $9.77 \mathrm{eV}$ [27], while adiabatic IEs of Ala were reported as $8.8 \mathrm{eV}$ [24] and $8.66 \mathrm{eV}$ [27]. Alanine's IEs determined by EI mass spectrometry with similar to the present experiments' electron energy resolution was $9.12 \pm 0.1 \mathrm{eV}$ [21]. High energy-resolution photoion mass spectrometry [29] was recently used to determine adiabatic EIs of Gly $(9.02 \pm 0.02 \mathrm{eV})$ and Ala $(8.75 \pm 0.05 \mathrm{eV})$. Additionally, charge transfer spectroscopy [43] has been utilized for this purpose with prediction of the EIs for Gly $(9.30 \mathrm{eV})$ and Ala $(9.63 \mathrm{eV})$. He-I [44] and $92 \mathrm{eV}$ synchrotron radiation [45] photoelectron spectroscopy was applied to study potential contribution of different Ala isomers into photoelectron spectrum at high temperatures; good matches with previous [27] photoelectron spectrum was reportedly achieved, but no numeric data were reported there. Photoelectron spectra of Ala in the soft X-ray region together with TOF spectra were published and intensive Ala fragmentation at low mass range was observed [46]. Complementary to photoelectron spectroscopy, electron momentum spectroscopy, EMS, [47, 48] dealt with experimental imaging of the electron density of binding energy valence electrons of Gly; high energy resolution was impossible to use in EMS experiments, but electron density imaging helped unambiguously assign the Gly' molecular orbitals. To conclude, except for data from references 23 and 43, the present data are found to be consistent with the previous literature data.

Additional protonated glycine and alanine ions, $[\mathrm{Gly}+\mathrm{H}]^{+}$and $[\mathrm{Ala}+\mathrm{H}]^{+}$, were simultaneously detected with their corresponding cation-radicals $\mathrm{Gly}^{+\bullet}$ and $\mathrm{Ala}^{+\bullet}$ (Fig. 2 and 3). This occurred when either the distance between probe tip and electron beam was shortened or when the probe was operated at increased temperature. Although very accurate probe temperature was impossible to measure in these experiments, an estimation of the probe adjustment of the conditions by applying higher or lower current through the probe was possible (see Experimental). Higher current and therefore higher probe temperature resulted in increased gas-phase sample density and thus frequency of collision events between neutral amino acids and the newly generated cation-radicals. One should note that due to thermal lability of amino acids, temperature dependence of the ion yield and chemical processes occurring during evaporation have been an issue since the first publications of EI mass spectra of amino acids [7, 10, 12]. It was reported that sublimation of Gly from a glass holder occurs without degradation up to $150-165{ }^{\circ} \mathrm{C}[48,49]$ and Ala up to $200{ }^{\circ} \mathrm{C}$ [49]. Employing an effusive cell (no details were presented, but presumably with metal walls) Snegursky and co-workers $[22,23,50]$ showed that thermal degradation of Gly was minimized within the temperature range $50-120{ }^{\circ} \mathrm{C}$. The present experiments support these observations in that introduction of 
Gly or Ala samples via either the DEP or commercial JEOL direct insertion probe with or without a glass container did not result in essential differences in the EI mass spectra up to $180{ }^{\circ} \mathrm{C}$. The instrument used in the present work is able to record 3-D spectra in real time (so, the fourth dimension is time) and each ToF scan is available via computer software. All scans were checked and in contrast to the earlier report [12], the present 4-D EI mass spectra of Gly and Ala did not show any notable differences over the recording time. Therefore, one can exclude surface reactions [51-53] that might occur with amino acids while depositing them on the DEP wire. The main reason of this, we believe is the fast heating of the DEP wire followed by fast evaporation of amino acids samples. It is known that adsorption on some metal surfaces may result in deprotonation of amino acids upon heating [51-53]. Recording the negative ion yield as function of electron energy showed that only known [54] resonance electron-molecule interactions at a characteristic energy range were involved in negative ion forming processes. Protonation as a result of similar sample-surface interactions can be also excluded since, as mentioned above, turning the filament off resulted in immediate removal of ion signal; at the same time, when the filament was on, ion yield increased over the noise level only at electron energies exceeding the ionization threshold (Figs. 4 and 5).

Under the experimental conditions utilized in the present work, Ala protonated species $[\mathrm{Ala}+\mathrm{H}]^{+}$ were generated more efficiently than Gly. In fact, at lower probe temperature and larger distances to the electron beam it was possible to practically suppress all formation of $[\mathrm{Gly}+\mathrm{H}]^{+}$(Fig. $\left.2 \mathrm{~A}\right)$. In contrast, the $[\mathrm{Ala}+\mathrm{H}]^{+}$was still recognizable in the EI mass spectrum (Fig. 3A) under otherwise identical conditions. Only at very low (threshold) DEP temperature when total ion intensity was so low that recording ionization efficiency curves versus electron energy was impossible, was the intensity of cation-radicals from Ala higher than that of $[\mathrm{Ala}+\mathrm{H}]^{+}$(see insert to Fig. 3(A)). These combined findings indicate that the protonated ions are likely a consequence of the "collisional" interactions of the cation-radicals and their corresponding neutrals. Comparison of relative intensities of $\mathrm{M}^{+\bullet}$ and $[\mathrm{M}+\mathrm{H}]^{+}$ions for Gly and Ala carried out at low and high DEP temperatures (Figs. 2 and 3) and therefore low or high sample densities supports this finding. If the intensity change of the $\mathrm{M}^{+\bullet}$ ions (as well as other ions but $[\mathrm{M}+\mathrm{H}]^{+}$) which is supposed to be linear with temperature (and therefore with vapor pressure), then the intensity of the $[\mathrm{M}+\mathrm{H}]^{+}$ions should change quadratically. As one can see from Figs. 2 and 3, the majority of ion intensities increase 1.3-1.8 fold with increasing temperature and decreasing distance of the DEP' tip with respect to the electron beam (and therefore increased sample vapor pressure); at the same time, protonated species increase their intensities $\sim 3$ (Gly) and 4 (Ala) fold. Provided that ions generated from amino acids via EI change their intensity linearly with vapor pressure, the variation of $[\mathrm{M}+\mathrm{H}]^{+}$ion intensities at the same conditions is clearly 
different and close to a quadratic dependence. The same quadratic dependence on temperature/pressure is expected if neutral dimers or higher aggregates of amino acids are formed via collisions prior to ionization. Both mechanisms for the dimer formation are indicative of intermolecular reactions in the ionization chamber [6] when molecular density is high enough to enable many-body collisions. There is no direct way in the present experiments to distinguish between them. Some experimental data, which will be discussed below in comparison to other published data, support the first scenario. Importantly, the IE of amino acids and $\mathrm{AE}$ of protonated amino acids are presumed to be identical for the two dimer formation mechanisms, namely dimer formation prior or after ionization. Thus, protonated amino acid formation may occur either by hydrogen atom abstraction from a neutral residue to the adjacent cation-radical or by proton transfer from the cation-radicals to the neutral residue. Since Ala is known as having higher vapor pressure than Gly when both are taken at the same temperatures $[55,56]$, it is not surprising that $[\mathrm{Ala}+\mathrm{H}]^{+}$ions are more abundant than $[\mathrm{Gly}+\mathrm{H}]^{+}$ions at similar experimental conditions.

It is interesting that the formation of dimers and higher clusters of amino acids embedded in helium nano-droplets [57-60] or co-embedded in helium droplets with water [59, 61] also resulted in the formation of intense protonated amino acids. Formation of these protonated species was supposed to proceed via fragmentation of pre-existed dimers or higher complexes in the effusive or molecular beams. Kresin and co-workers [60] recently separated dimer formation of amino acids spatially and observed either quadratic or linear dependence of intensities of protonated ions on temperature/pressure depending on two-body collisions or unimolecular proton transfer (at fixed density of one of the components of the collision system, namely basic amino acid histidine, that served as a proton acceptor) were involved in the generation of protonated amino acids.

In contrast to helium-droplet experiments [57-61], no ion peaks corresponding to dimers or higher clusters of Gly and Ala were observed in the present experiments. Even if they might form via collisions with increased sample pressure, amino acid aggregates most probably did not survive without cooling under the conditions of the present experiments and this fact is in favor of the formation mechanism that protonated species are produced via collision of neutrals and cation-radicals and not from neutral clusters followed by ionization. In the case of Gly, another higher than mass of the molecular radical cation ion peak with $105 \mathrm{~m} / \mathrm{z}$ (supposedly $\left[\mathrm{Gly}+\mathrm{NH}_{2} \mathrm{CH}_{2}\right]^{+}$. ions) was observed in the mass spectrum with less than $0.5 \%$ intensity with respect to that of $[\mathrm{Gly}+\mathrm{H}]^{+}$. As shown previously $[58,59]$, the production of these ions of very high abundance comparable to protonated amino acids might be an indication of the dimer formation in amino acids prior to ionization. However, very week intensity of the $\left[\mathrm{Gly}+\mathrm{NH}_{2} \mathrm{CH}_{2}\right]^{+}$• ions in 
Gly and the absence of analogous $\left[\mathrm{Ala}+\mathrm{NH}_{2} \mathrm{CHCH}_{3}\right]^{+}$. ions in the mass spectrum of Ala (m/z 133), where intensity of protonated $[\mathrm{Ala}+\mathrm{H}]^{+}$was even higher than $[\mathrm{Gly}+\mathrm{H}]^{+}$, again show that formation of neutral amino acid dimers prior ionization in the present experiments is probably a less efficient process in forming protonated amino acids than collisions of charged and neutral amino acids. Finally, convolution of the theoretical ionization efficiency curves (obtained with a non-linear Marquardt-Levenberg algorithm fitting technique $[41,42]$ ) with a Gaussian function of the same width as the electron beam energy spread gave much better fits with the experimental curves than with a Gaussian function of higher width. This again supports the mechanism for the dimer formation via collision of charged and neutral species rather than dimer formation via collision of neutral species because in the last case internal vibrational energy of the dimers would be approximately twice as large and therefore the contribution from the hot bands in the region of the ionization threshold would be expected to be stronger. If this was the case, the Gaussian fit with higher width should be the superior fit to the experimental data, but it is not. Finally, the ionization efficiency curves of the most abundant fragment ions, $\mathrm{H}_{2} \mathrm{NCHR}^{+}\left(\mathrm{R}=\mathrm{H}\right.$ (Gly) and $\mathrm{CH}_{3}$ (Ala)) were also recorded (Figs. 4C and 5C, respectively). For Gly, the appearance energy (AE) of the immonium ion, $\mathrm{H}_{2} \mathrm{~N}^{+}=\mathrm{CH}_{2}$ was determined to be $9.4 \mathrm{eV}, 0.3 \mathrm{eV}$ greater than that of the cation-radical, Gly ${ }^{+\bullet}$ (Fig. 4). In contrast, the $\mathrm{AE}$ of the immonium ion, $\mathrm{H}_{2} \mathrm{~N}^{+}=\mathrm{CHCH}_{3}$ of the Ala form was found to be identical to the IE of the Ala within experimental error (Fig. 5). Consequently, we have a difference between these two nominally very similar amino acids which needs to be accounted for.

It should be noted that present $\mathrm{AE}$ of the immonium ion in Gly is very close to the most recent photoionization value $9.38 \pm 0.05 \mathrm{eV}$ [29] which are lower than previous EI data $10.1 \pm 0.2 \mathrm{eV}$ [7], 10.23 \pm $0.09 \mathrm{eV}[8], 10.27 \pm 0.05 \mathrm{eV}$ [9] and $10.1 \pm 0.1 \mathrm{eV}[22,23]$ obtained via vanishing current method, semilogarithmic plot of the ionization curve and similar to the present fitting technique. A possible explanation of the discrepancy between photo- [29] and earlier electron ionization techniques [8, 9] was in better detection efficiency at threshold in the case of photoionization MS in comparison to EI MS [29]. Analysis of the immonium ion ionization efficiency curve for Gly with a non-linear Marquardt-Levenberg algorithm fitting technique clearly demonstrates two features on the curve at 9.4 and $10.25 \mathrm{eV}$ (Fig. S1). Consequently, it was possible that the first threshold $(9.4 \mathrm{eV})$ was inadvertently omitted in earlier EI experiments when operating with linear extrapolation to zero ion current techniques due to low ion signal. In references 22 and 23, an accuracy of the electron energy accuracy was claimed as $0.1 \mathrm{eV}$ (no energy resolution was reported); a brief analysis of their $\mathrm{Ar}^{+}$ionization efficiency curve and exploited electron beam current of 30-50 $\mu \mathrm{A}[22]$ together with the claimed energy step change of only $0.1 \mathrm{eV}$ [23] put their 
$0.1 \mathrm{eV}$ accuracy into doubts. Most probably, $0.1 \mathrm{eV}$ was the standard deviation determined with a nonlinear Marquardt-Levenberg algorithm fitting technique, but not accuracy. Most probably, similar to the earlier EI experiments [8, 9], real threshold at lower energy was omitted in references 20 and 21 too.

With respect to Ala, the present $\mathrm{AE}$ of the immonium ion $(8.9 \pm 0.1 \mathrm{eV})$ is rather close to the

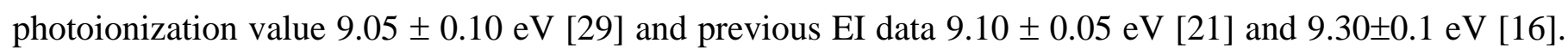
In contrast to Gly, consideration of the immonium ion in Ala with a non-linear Marquardt-Levenberg algorithm fitting technique indicated only one feature in its ionization efficiency curve at 8.90 eV (Fig. S2 for Ala).

Our experimental findings don't provide an answer for whether $\mathrm{H}^{\bullet}$ or $\mathrm{H}^{+}$transfer is responsible for generation of the protonated ions. Consequently, we have calculated several potential pathways to help enable a choice between alternatives using density functional and ab initio theory (see next section).

\section{(2) Calculation Results}

(a) Amino Acid and Cation-radical Minima

Spatial structures of Gly and Ala in different charge forms studied in details both experimentally and theoretically in a number of publications and it is impossible to quote all of them; only some of these works that are relevant to the present study will be considered for comparison. Yu et al. [62] calculated positive ions of Gly at the G2(MP2/6-31G(D)) level of theory and found several stable isomers of Gly ${ }^{+\bullet}$. Interesting enough is that the 1N-I Cs isomer (Scheme 1, nomenclature for the Gly cation-radical isomers in Ref 62) that has direct relationship to the most stable neutral Gly isomer (2-I) was not found to be the most stable isomer. The obvious caveat being that formation of these other isomers requires intramolecular rearrangement which will have substantial barriers impassable without substantial activation. Three other isomers (4 Cs, 1C-1 Cs and 1C-II Cs) were predicted [62] to have lower energy than the 1N-I isomer at the G2(MP2/6-31G(d)) level of theory. Similar results were reported in recent theoretical work [13, 63]. In the present study, these $\mathrm{Gly}^{+\bullet}$ isomers were treated at the MP2/aug-cc-pvdz level of theory and again the $4 \mathrm{Cs}$, 1C-1 Cs and 1C-II Cs isomers were found with lower energy than the 1N-I isomer. Comparison with experimental adiabatic electron energy (9.10 eV, Fig. 4A) matched more closely with the theoretical value for the $1 \mathrm{~N}-\mathrm{I}$ isomer $(9.16 \mathrm{eV}$; includes zero-point energy corrections) at the MP2/aug-cc-pvdz level of theory. For comparison, adiabatic EIs for other isomers were predicted to be as the following: $8.22 \mathrm{eV}$ for the $4 \mathrm{Cs}$ isomer; $8.69 \mathrm{eV}$ for the $1 \mathrm{C}-\mathrm{I}$ isomer; $8.94 \mathrm{eV}$ for the $\mathrm{C}-\mathrm{II}$ isomer. Reliability and quality of the 
MP2/aug-cc-pvdz level of theory for Gly species was supported by comparison of experimental (10.0 eV $[24,25])$ and theoretical $(10.1 \mathrm{eV})$ vertical ionization energies.

Similar results at the MP2/aug-cc-pvdz level of theory were obtained for Ala positive ion isomers (the same nomenclature as for Gly in Scheme 1) as well. Experimental adiabatic EI (8.90 eV, Fig. 5A) matches well with that of the $1 \mathrm{~N}-\mathrm{I}$ isomer (8.95 eV with zero-point correction). For other Ala isomers adiabatic EIs were predicted as the following: $7.99 \mathrm{eV}$ for the $4 \mathrm{Cs}$ isomer; $8.33 \mathrm{eV}$ for the $1 \mathrm{C}-\mathrm{I}$ isomer; $8.54 \mathrm{eV}$ for the 1C-II isomer. Comparison between experimental (9.85 eV [25]) and theoretical vertical EI (9.90 eV) confirms that the MP2/aug-cc-pvdz level of theory works well for Ala too. Given that the experimental and theoretical EIs matched much better for the 1N-I isomer than for other lower energy isomers for both Gly and Ala, theoretical protonation pathways were considered below only for the $1 \mathrm{~N}-\mathrm{I}$ isomer. Logically, this fits with the envisaged major difficulty in forming these structures from $1 \mathrm{~N}-1$.

\section{(b) Cation-radical Reactions: Formation of Protonated Amino Acids}

Gas-phase hydrogen and/or proton transfer between neutral glycine or alanine and their cationradicals are considered theoretically and compared with experimental data. Our combined calculations indicate that the barrier to formation of protonated glycine is lowest for proton abstraction mechanisms. In fact, attempts to perform $\mathrm{H}^{\bullet}$ abstraction reactions from a neutral glycine or alanine residue to their adjacent cation-radical congener were unsuccessful and failed to converge, or optimized to proton transfer transition structures. So, the answer to the question raised in our title appears to be no, at least for the amino acids studied in the present work. Consequently we shall now discuss the most favorable $\mathrm{H}^{+}$transfer reactions; (1) $\mathrm{C}_{\text {alpha }}$ proton abstraction and (2) C-terminal proton abstraction (Scheme 2, Schemes S1 and S2).

The first mechanism involves abstraction of a $\mathrm{C}_{\text {alpha }}$ proton from the cation radical by the adjacent neutral residue in the dimer. Based on this we require the $\mathrm{Gly}^{\bullet+}$ and glycine dimer to have at least $\sim 0.20$ $0.24 \mathrm{eV}$ of energy (dependent on level of theory, Table 1) in order to observe the protonated form. All levels of theory investigated here give similar results. This type of proton abstraction barrier in a singly charged complex is comparatively low $(<25 \mathrm{~kJ} / \mathrm{mol})$, which is consistent with a proton transfer mechanism.

Prior work on singly-charged radical-cation complexes of similar size and constituents [65-67] showed proton transfer was possible at similarly low energy levels and that the alternate $\mathrm{H}^{\bullet}$ abstraction reactions required a greater range of energies. It should be noted however that those calculations showed significant variation as a function of structure and are comparatively hydrogen rich systems [68, 69] relative to the present situation, which likely affects the available pathways. This reaction generates a highly favorable 
product dimer of $[\mathrm{Gly}+\mathrm{H}]^{+}$and neutral $\mathrm{H}_{2} \mathrm{NC}^{\bullet} \mathrm{HCO}_{2} \mathrm{H}$ which then dissociates at energies very similar to that of the lowest energy $\mathrm{Gly}^{\bullet+}$ and glycine dimer. i.e., the transition structure is the rate-determining step.

In contrast to the relatively high degree of theoretical agreement for the preceding $\mathrm{C}_{\text {alpha }}$ proton transfer reaction, calculations on the C-terminal deprotonation reaction mechanism show considerably more variation (Table 1). The density functional methods are in qualitative agreement, but range from requirements of at least $0.26(\mathrm{~B} 3 \mathrm{LYP})$ to $0.53 \mathrm{eV}(\mathrm{M} 06-2 \mathrm{X})$ to generate the product-limited $[\mathrm{Gly}+\mathrm{H}]^{+}$. The MP2 single point calculations from the B3LYP optimized structures strongly disfavor the reactive configuration $(96.1 \mathrm{~kJ} / \mathrm{mol}, 1.0 \mathrm{eV})$ and to a lesser extent the proton transfer transition structure. This is naturally transferred to the weighted, B3LYP-MP2 energies too, resulting in relatively high, rate-limiting energies of at least $55.7 \mathrm{~kJ} / \mathrm{mol}(0.58 \mathrm{eV})$. Clearly, there's a major difference in how the models describe this chemical reaction, but how does this all compare to experiment?

Experimentally, we observe the $\mathrm{Gly}^{+\bullet}$ cation-radical at $9.1 \pm 0.1 \mathrm{eV}$ and the $[\mathrm{Gly}+\mathrm{H}]^{+}$ion at $9.4 \pm 0.1$ $\mathrm{eV}$ giving a barrier of $0.3 \pm 0.14 \mathrm{eV}$. This is generally more consistent with the barriers calculated for the $\mathrm{C}_{\mathrm{alpha}}$ proton abstraction (Table 1) than those for the C-terminal deprotonation reaction mechanism, although the B3LYP/6-311++G(2d,p) barriers are similar for the proton transfer reaction. We then analyzed the data further using microcanonical rate coefficient calculations to determine if obvious kinetic differences were present between the two pathways. These calculations indicate (Figure 6A) that the $\mathrm{C}_{\mathrm{alpha}}$ proton abstraction is favored at the timescale of our instrument $\left(\geq 10^{6} \mathrm{~s}^{-1}\right)$ and has the correct onset energy of $\sim 0.3 \mathrm{eV}$. At higher internal energy (and larger rate constant), the C-terminal deprotonation transfer reaction mechanism becomes increasingly competitive with curve crossing occurring at $\sim 0.45 \mathrm{eV}\left(\sim 2 \times 10^{7}\right.$ $\mathrm{s}^{-1}$ ). This mechanism also has an onset $\sim 0.35 \mathrm{eV}$ within our experimental error, so it is likely that both will be active, but to varying extents for the Glycine system.

The calculated $\mathrm{C}_{\text {alpha }}$ proton abstraction barriers in the alanine system are relatively consistent between the different modeling approaches (26.4-36.3 kJ/mol (0.27-0.38 eV), Table 2). This exothermic reaction generates protonated alanine and $\mathrm{H}_{2} \mathrm{NCH}_{3} \mathrm{C}^{\bullet} \mathrm{CO}_{2} \mathrm{H}$. As the experimental values for Ala ${ }^{+\bullet}$ cationradical detection was $8.9 \pm 0.1 \mathrm{eV}$ and the $[\mathrm{Ala}+\mathrm{H}]^{+}$ion at $9.2 \pm 0.1 \mathrm{eV}$, a barrier of $0.3 \pm 0.14 \mathrm{eV}$ is again present. Thus, all of the calculated $\mathrm{C}_{\mathrm{alph}}$ proton abstraction barriers are within the experimentally determined range. Once again, the alternative C-terminal deprotonation reaction mechanism shows considerable variation in calculated barriers (Table 2); the approaches including second order MøllerPlesset single point calculations provide substantial overestimates (91.1 and $53.7 \mathrm{~kJ} / \mathrm{mol}$, (0.94 and 0.56 $\mathrm{eV})$ ) of the experimentally determined barrier. It should be noted that this includes a reactive configuration 
structure that the MP2 single point energy places as higher than the TS energy; these numbers reflect the substantial disagreement between MP2 and B3LYP in describing the chemistry. Furthermore, the productlimited M06-2X mechanism $(0.49 \mathrm{eV})$ overestimates the energy necessary to form protonated alanine ions. Somewhat surprisingly, this leaves B3LYP as the best predictor of the experimental barrier as both the proton transfer mechanisms fall within the experimentally determined limits. In marked contrast to the situation for glycine, for protonated alanine formation microcanonical rate constant calculations (Figure 6B) predict the $\mathrm{C}$-terminal proton abstraction mechanism to be the dominant process on the timescale of the experiment, as the $\mathrm{C}_{\mathrm{alph}}$ proton abstraction mechanism requires $\geq 0.5 \mathrm{eV}$ internal energy to provide a rate constant of $10^{6} \mathrm{~s}^{-1}$. The microcanonical rate coefficient for the $\mathrm{C}$-terminal deprotonation mechanism indicates a rate constant at $10^{6} \mathrm{~s}^{-1}$ (at $0.3 \mathrm{eV}$ ) rising to $10^{7} \mathrm{~s}^{-1}$ (at $0.4 \mathrm{eV}$ ) well within the experimental accuracy. It should also be noted that for completeness, microcanonical rate coefficient calculations were performed using the results of our other calculations at other levels of theory too. Unsurprisingly given the results in Tables 1 and 2, these data provided poor fits to the experimental data (not shown).

\section{(c) Formation of Immonium Ions: Cation-radical Reactions?}

In addition to generation of protonated residues, our experiments showed substantial production of immonium ions, $\mathrm{RCHNH}_{2}{ }^{+}$(Scheme $2 \mathrm{c}$ ). For Gly these ions we initially observed at $9.4 \pm 0.1 \mathrm{eV}$ giving a barrier of $0.3 \pm 0.14 \mathrm{eV}$, whereas for Ala these ions we observed at the same energy $(8.9 \mathrm{eV})$ as the cationradical, $\mathrm{Ala}^{+\bullet}$. i.e., barrierless or a very low barrier $(<0.1 \mathrm{eV})$. Practically this means that in principle, the Gly immonium ion can be generated from either the cation-radical or the protonated form, whereas the Ala form very likely comes from the cation-radical. How do the various processes compare theoretically?

Table 3 summarizes the energetics calculated for the various reactions involving either cation radicals or protonated residues. It is immediately clear that the reaction is highly unlikely to occur from the protonated ion as this requires at least 1.41-1.72 eV for Gly and 1.32-1.50 eV for Ala. This agrees with the experimental finding that alanine immonium ions are formed at energies lower than protonated alanine residues. However, what's much less obvious is the energy difference between the theoretical and experimental data on Gly immonium ion formation. The calculated transition structures (Table 3) are lower than the separated product energies, which require $0.49-0.87 \mathrm{eV}$ to access for the Gly cation radical. The density functional methods both predict less favorable products than the B3LYP-MP2 and the MP2 single

point calculation approaches. Thus, the calculations all appear to overestimate the barrier to $\mathrm{H}_{2} \mathrm{CNH}_{2}{ }^{+}$ formation. An alternate possibility is that the experimental temperature and that of our calculations differs 
enough that the Gly cation radicals are formed from either thermally excited or higher energy glycine structures which reduces the practical barrier necessary to overcome.

A similar argument can be made in the case of the Ala cation radicals and as they have generally lower separated product energies $0.35-0.62 \mathrm{eV}$ than their Gly counterparts (Table 3), this could potentially be extended to explain the lack of an experimentally detectable barrier to dissociation. In potential support of this, is the fact that Ala sublimes at a higher temperature than glycine $\left(258 \mathrm{vs} .233^{\circ} \mathrm{C}\right)$ and has a greater sublimation enthalpy $(144.8 \pm 4.2 \mathrm{~kJ} / \mathrm{mol}$ vs. $138.1 \pm 4.6 \mathrm{~kJ} / \mathrm{mol})$ [11]. This explanation is potentially complicated by the documented tendency of Ala to thermally degrade at temperatures at or above the sublimation temperature [11] thereby enabling electron ionization of the thermally degraded alanine components rather than dissociation from the newly formed cation-radical. However, as discussed in the preceding Experimental, and Results and Discussion sections, the temperature in our experiments is unlikely to exceed $150{ }^{\circ} \mathrm{C}$ (and is more realistically lower $\sim 100-120{ }^{\circ} \mathrm{C}$ ). Thus, we do not expect thermally degraded Ala to be present in our experiment. This contention is supported by data from the NIST database; $\mathrm{CHCH}_{3} \mathrm{NH}_{2}$, which would be present as a thermal degradation product of Ala has EI threshold of only 5.7 $\mathrm{eV}$, yet we detect no such low energy onset. Similarly for Gly, $\mathrm{NH}_{2} \mathrm{CH}_{2}$ has IE threshold $6.29 \mathrm{eV}$ which we also see no evidence of.

As was mentioned above, the previously reported EI appearance energies for the Gly immonium $\mathrm{RCHNH}_{2}{ }^{+}$ions provided substantially higher onset values $(10.23 \pm 0.09 \mathrm{eV}$ [8] and $10.27 \pm 0.05 \mathrm{eV}$ [9]) than the present data $(9.4 \pm 0.10 \mathrm{eV})$. We also detect an analogous onset at $10.25 \pm 0.10 \mathrm{eV}$ (Fig. S1). In contrast the photoionization data [29] show adiabatic IE of the cation-radicals and AE of the immonium ions for Gly $(0.36 \mathrm{eV})$ which is within our experimental range. However, this same photoionization study [29] has the Ala immonium ion appearance energy $0.3 \mathrm{eV}$ above the Ala cation radical threshold, whereas we detect $\mathrm{H}_{3} \mathrm{CHCNH}_{2}{ }^{+}$at electron energies that are indistinguishable from Ala ${ }^{+\bullet}$ formation. It's unclear why this discrepancy exists.

\section{Conclusions}

Gas-phase collisions of Gly and Ala with free electrons were employed to form their positive ions at well determined energies. A direct exposure probe was utilized to transport the residues into the instrument where rapid heating vaporized them into the gas-phase. EI mass spectra and ionization efficiency curves of molecular radical-cations, protonated residues, and some fragment cations were recorded as a function of electron energy. The yield of $[\mathrm{Gly}+\mathrm{H}]^{+}$and $[\mathrm{Ala}+\mathrm{H}]^{+}$depends on the pressure of molecular vapor pressure 
in the ionization chamber. The molecular density was increased by elevating the temperature of the DEP and/or reducing the distance between the probe's tip and the electron beam. The appearance energies of $[\mathrm{Gly}+\mathrm{H}]^{+}$and $[\mathrm{Ala}+\mathrm{H}]^{+}$were both determined as $0.30 \pm 0.14 \mathrm{eV}$ higher than the ionization energies of their $\mathrm{M}^{+\bullet}$ congeners. These findings indicate that the protonated species are a consequence of the interactions respectively of $\mathrm{Gly}^{+\bullet} / \mathrm{Ala}^{+\bullet}$ and their corresponding neutrals when their densities in the ionization chamber were high enough to enable many-body collisions, i.e., either hydrogen transfer from neutral molecules to their cation-radicals or alternatively, proton transfer from the radical-cations to the neutrals were involved to form the protonated $[\mathrm{Gly}+\mathrm{H}]^{+}$and $[\mathrm{Ala}+\mathrm{H}]^{+}$.

All of our theoretical data supports proton transfer reactions as the likely $[\mathrm{M}+\mathrm{H}]^{+}$forming method. For glycine, the data support abstraction of a $\mathrm{C}_{\text {alpha }}$ proton from the cation radical within the dimer by the neutral glycine residue at lower energies with microcanonical rate constant calculations (utilizing the B3LYP calculated frequencies and relative energies) indicating the alternate $\mathrm{C}$-terminal proton abstraction becomes more competitive at higher energies. A mixture of these processes is most consistent with the data on the timescale of our instrument. In contrast, the microcanonical rate constant calculations always favor the C-terminal proton abstraction mechanism for alanine. While there was relatively consistent agreement between the various levels of theory utilized here in description of the relative $\mathrm{C}_{\text {alpha }} \mathrm{H}^{+}$abstraction reaction, the C-terminal proton abstraction proved to be much more troublesome. It should be noted however, that the agreement between experiment and the other theoretical calculations (M06-2X, B3LYPMP2 mixed) was substantially worse than this.

Finally, substantial immonium ion formation was observed at experimental energies identical to the protonated product for Gly. In contrast the Ala congener occurred at energies indistinguishable from those of the $\mathrm{Ala}^{+\bullet}$ cation radical indicating formation of this type of ion occurred at the threshold. Theoretical barriers to $\mathrm{M}^{+\bullet}$ cation radical fragmentation to $\mathrm{HRCNH}_{2}{ }^{+}$indicate that they are product-limited and that the Gly barriers are generally larger than those for Ala, which is qualitatively consistent with the experimental result.

\section{Acknowledgments}

This work was supported by the National Science Foundation under Grant No. 0924027, the National Institutes of Health under Grant No. 1R01RR026275-01, the Environmental Health Sciences Center Grant (ES000240) from the National Institute of Environmental Health Science, and a grant from OSU RERF. BJB acknowledges start-up funds from the University of Missouri-St. Louis. Calculations were performed locally and at the Missouri Science and Technology Cluster in Rolla, MO. 


\section{Supporting Information}

Supporting information and figures which describe the fitting algorithm parameters utilized in this manuscript are provided.

\section{Figures and Figure Legends}

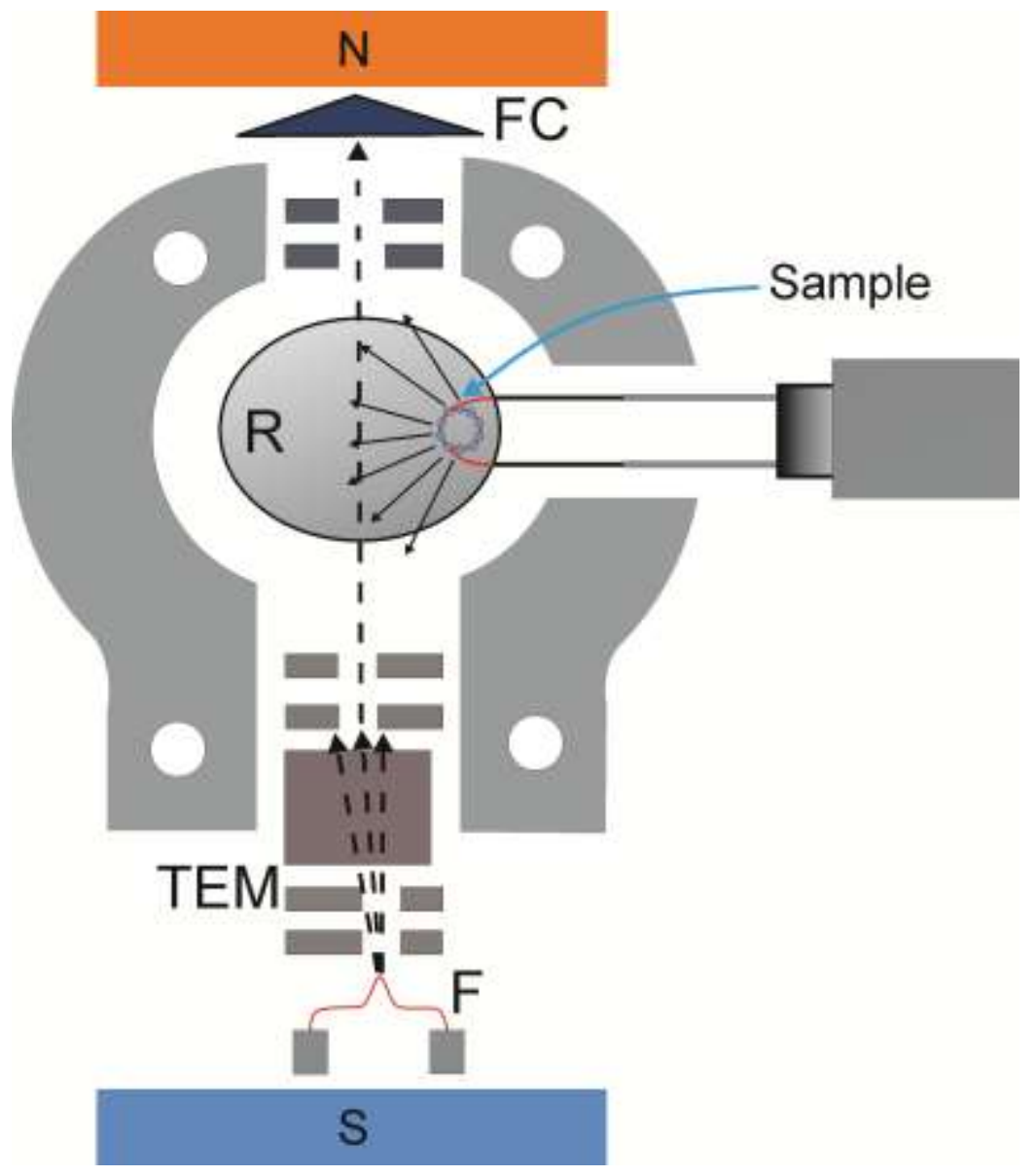

Figure 1. Schematic of ion chamber with direct exposure probe. F: filament, R: ion repeller, FC: Faraday cup (electron collector), $\mathrm{N} \& \mathrm{~S}$ poles of collimating magnet, TEM: trochoidal electron monochromator. 

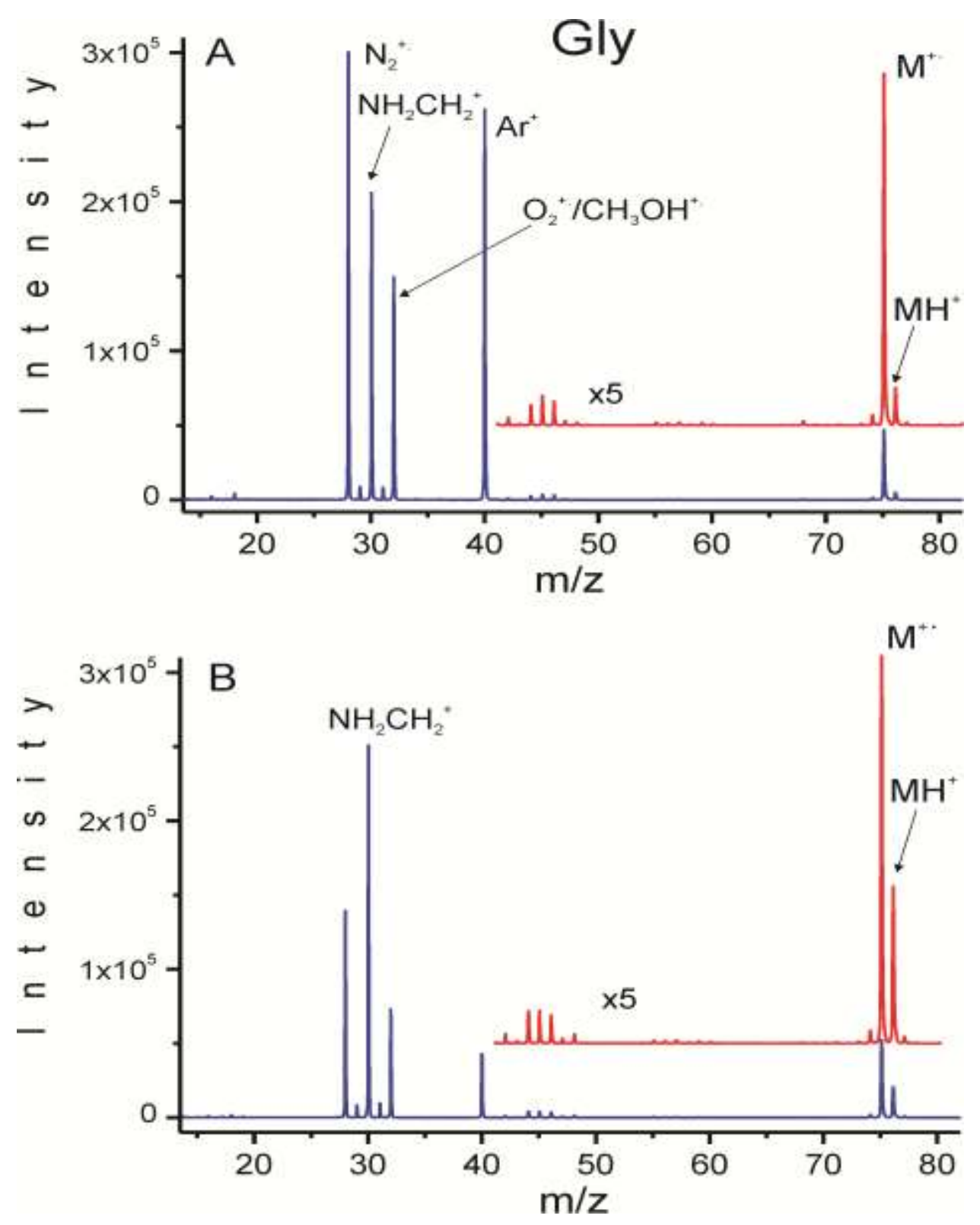

Figure 2. Electron ionization (EI) mass spectrum of Gly when electron energy was ramped over 0-25 eV. $\mathrm{Ar}^{+}(\mathrm{m} / \mathrm{z} 40)$ and $\mathrm{N}_{2}{ }^{+}(\mathrm{m} / \mathrm{z} 28)$ and $\mathrm{O}_{2}{ }^{+}(\mathrm{m} / \mathrm{z} 32)$ from air were used for calibration of mass scale. Due to not complete vaporization of methanol, contribution of $\mathrm{CH}_{3} \mathrm{OH}^{+}$into $\mathrm{m} / \mathrm{z} 32$ is also visible. A) EI mass spectrum was recorded with a distance between the DEP tip and the electron beam of $\sim 10-15 \mathrm{~mm}$ and low DEP temperature; B) EI mass spectrum was recorded with a distance between the DEP tip and the electron beam of $\sim 5-8 \mathrm{~mm}$ and high DEP temperature. The symbol $\mathrm{M}$ is used for the analyte, Gly. 

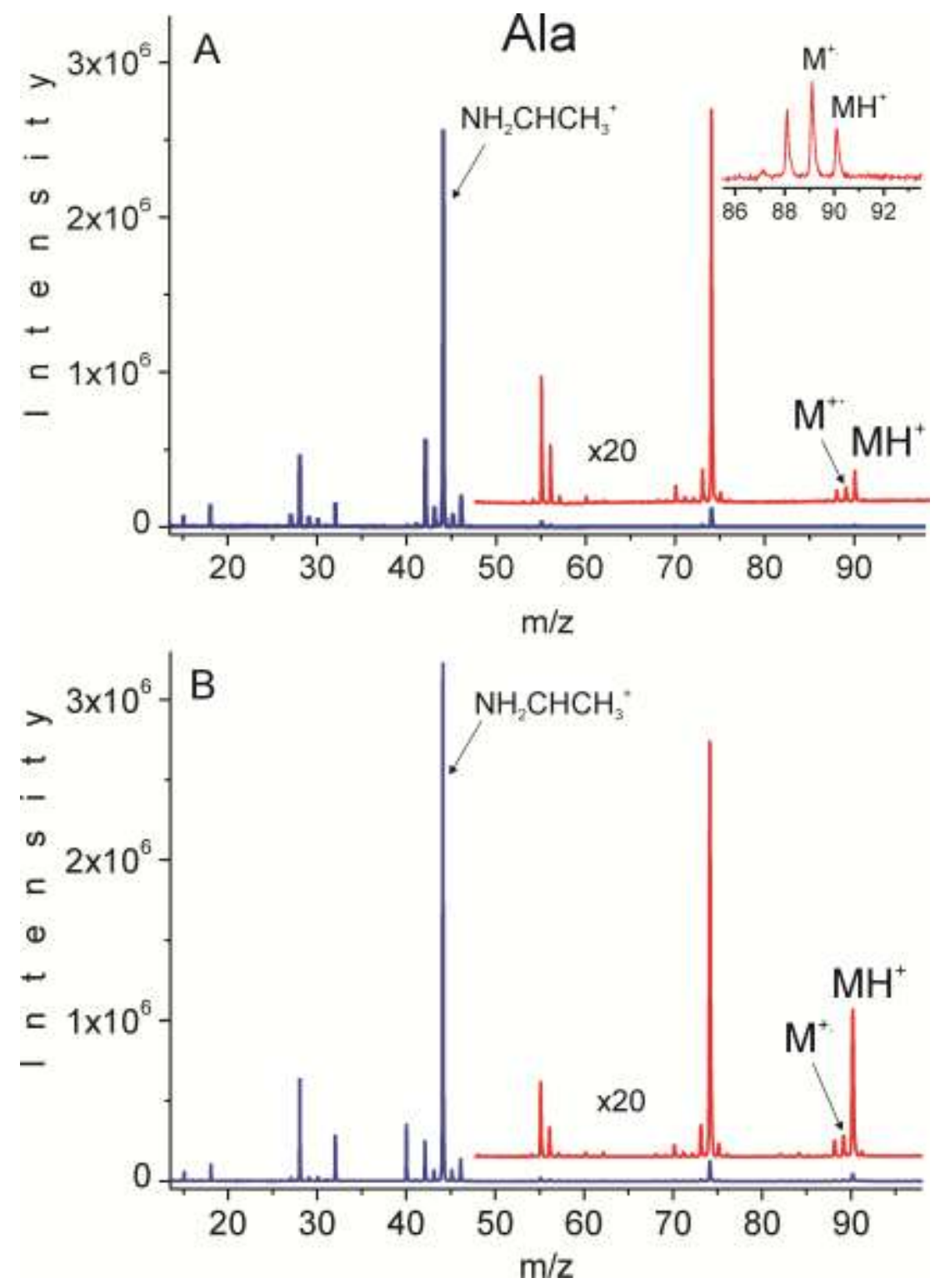

Figure 3. Electron ionization (EI) mass spectrum of Ala when electron energy was ramped over 0-25 eV. $\mathrm{Ar}^{+}(\mathrm{m} / \mathrm{z} 40)$ and $\mathrm{N}_{2}{ }^{+}(\mathrm{m} / \mathrm{z} 28)$ and $\mathrm{O}_{2}{ }^{+}(\mathrm{m} / \mathrm{z} 32)$ from air (not marked in the mass spectra) were used for calibration of mass scale. A) EI mass spectrum was recorded with a distance between the DEP tip and the electron beam of $\sim 10-15 \mathrm{~mm}$ and low DEP temperature; inset in (A) shows EI mass spectrum in the molecular cation-radical range at the threshold (lowest possible) temperature; B) EI mass spectrum was recorded with a distance between the DEP tip and the electron beam of $\sim 5-8 \mathrm{~mm}$ and high DEP temperature. The symbol $\mathrm{M}$ is used for the analyte, Ala. 


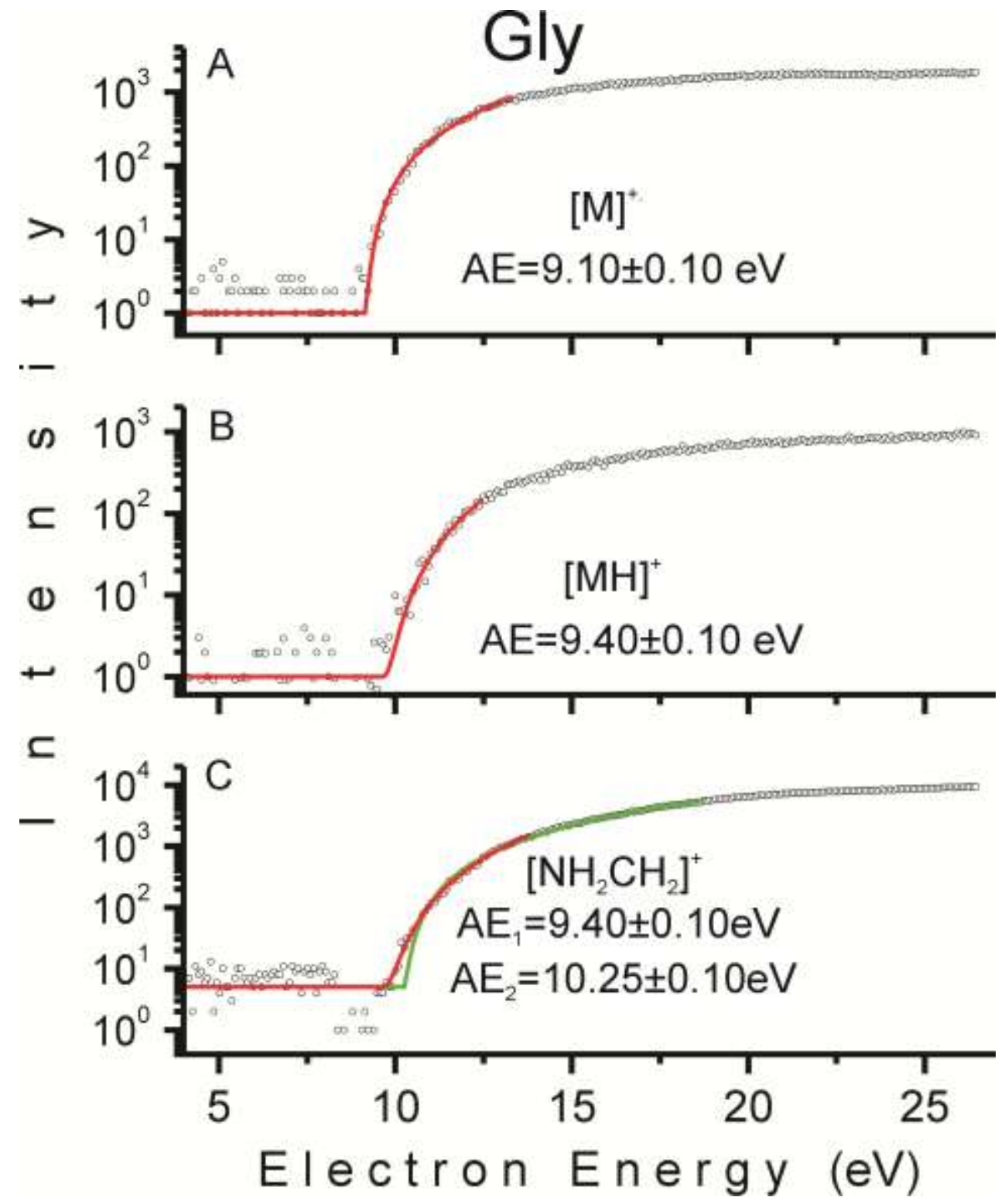

Figure 4. Gly electron ionization efficiency curve for A) m/z $75\left([\mathrm{M}]^{+*}\right)$, B) m/z $76\left([\mathrm{MH}]^{+}\right)$after subtraction of the ${ }^{13} \mathrm{C}$ contribution of $\left.[\mathrm{M}]^{+}, \mathrm{C}\right) \mathrm{m} / \mathrm{z} 30\left(\left[\mathrm{NH}_{2} \mathrm{CH}_{2}\right]^{+}\right)$ions all as functions of electron energy plotted on a semi-logarithmic scale. Experimental curves are open circles; red lines are theoretical curve obtained with a non-linear MarquardtLevenberg algorithm fitting technique [22] to determine the ions' appearance energies. The experimental conditions are close to that in Fig. 2B. Green curve in (C) shows second appearance energy for $\mathrm{m} / \mathrm{z} 30$ that probably corresponds to generation of the $\left[\mathrm{NH}_{2} \mathrm{CH}_{2}\right]^{+}$ions from excited state. 


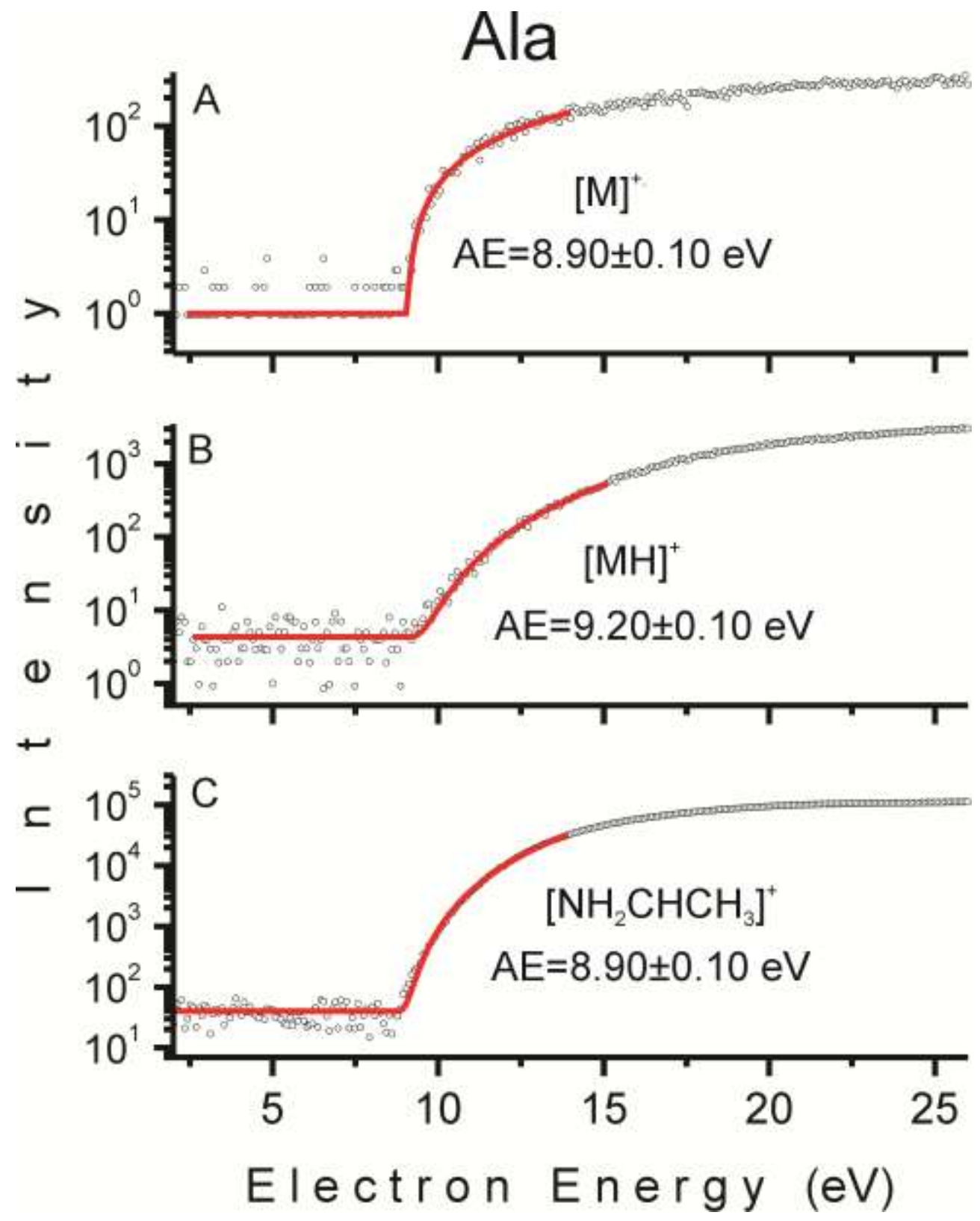

Figure 5. Ala electron ionization efficiency curve for A) m/z $\left.89\left([\mathrm{M}]^{+*}\right), \mathrm{B}\right) \mathrm{m} / \mathrm{z} 90\left([\mathrm{MH}]^{+}\right)$after subtraction of the ${ }^{13} \mathrm{C}$ contribution of $\left.[\mathrm{M}]^{+}, \mathrm{C}\right) \mathrm{m} / \mathrm{z} 44\left(\left[\mathrm{NH}_{2} \mathrm{CHCH}_{3}\right]^{+}\right)$ions as functions of electron energy plotted on a semi-logarithmic scale. Experimental curves are open circles; red lines are theoretical curve obtained with a non-linear Marquardt-Levenberg algorithm fitting technique [22] to determine the ions' appearance energies. The experimental conditions are close to that in Fig. 3B. 

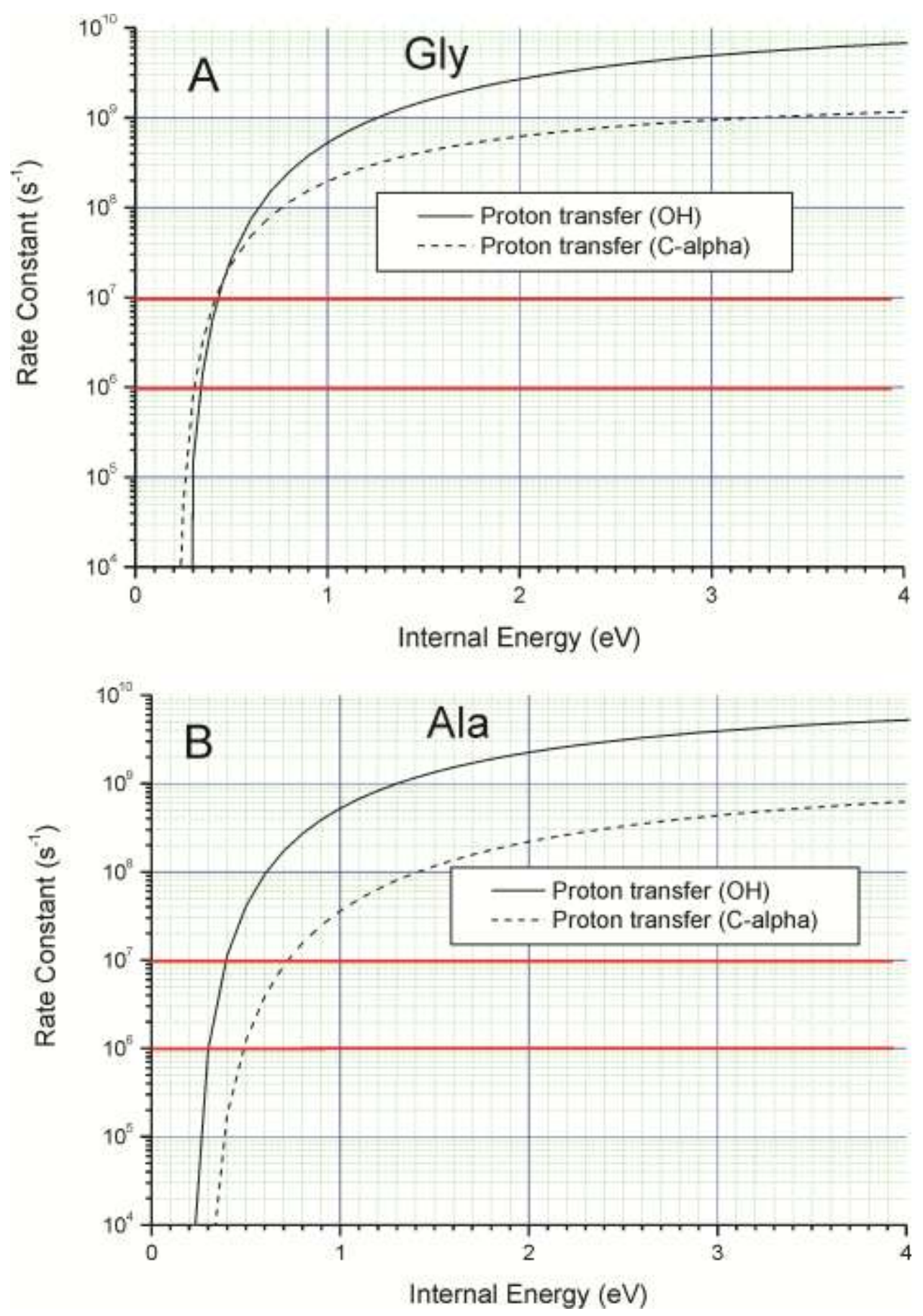

Figure 6. Microcanonical rate constants for unimolecular decomposition of A) $\mathrm{Gly}^{+\bullet}$, and B) $\mathrm{Ala}^{+\bullet}$. Calculated utilizing data from the UB3LYP energy and frequency calculations. Frequencies of TS and the global minimum dimer were used to calculate the sum of states and density of states, respectively. Two red horizontal lines in (A) and (B) indicate experimental time domain in the present experiments. 
Scheme Legends

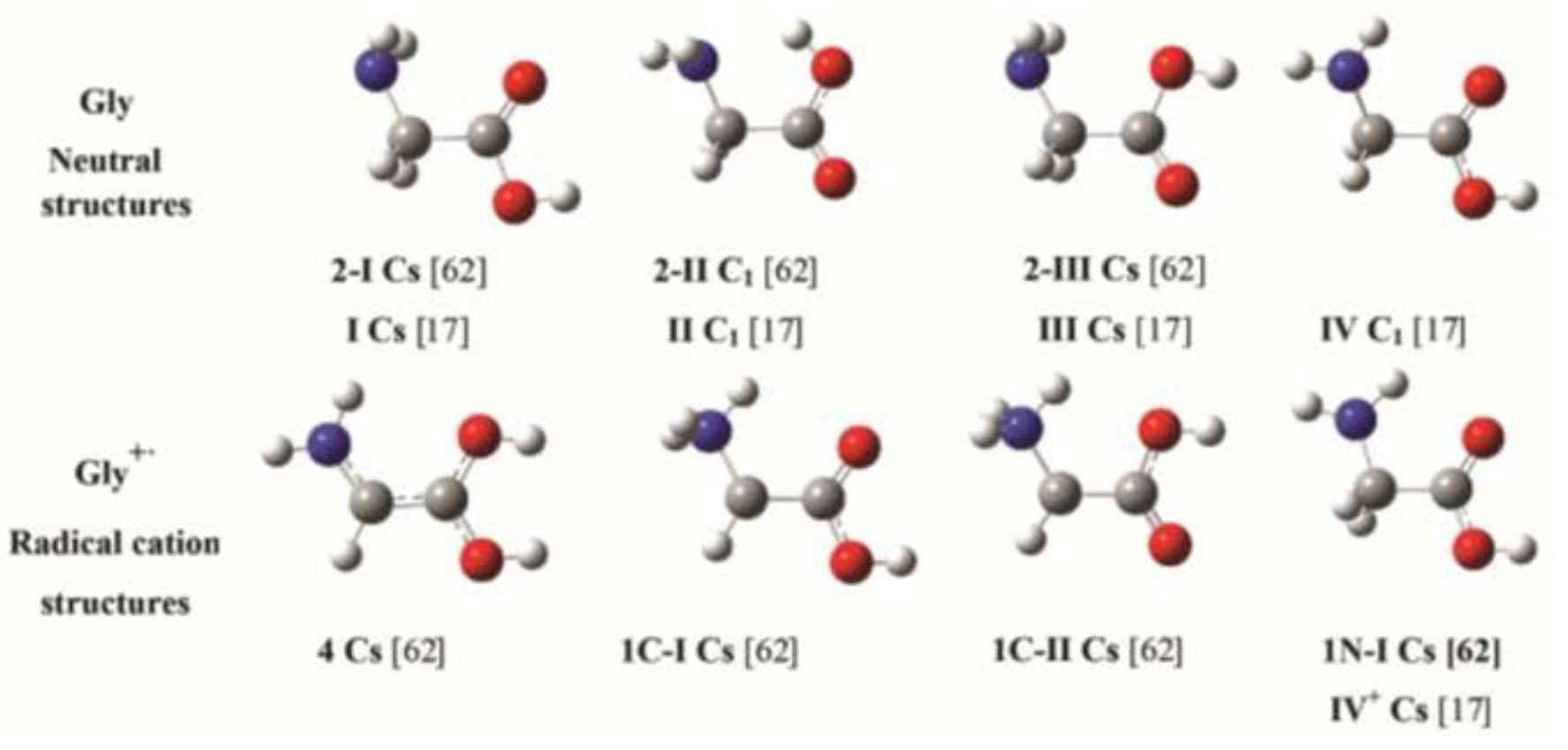

Scheme 1 On the top panel are the MP2/aug-cc-pvdz structures for the most stable isomer of neutral Gly (2-I Cs according to the nomenclature [62] or I Cs according to nomenclature [17] and three other isomers of neutral Gly: 2-II $\mathrm{C}_{1}$ [62] (II C $\mathrm{C}_{1}$ [17]; 2-III Cs [62] (III Cs [17] ); IV $C_{1}$ [17]. On the bottom panel are four isomers of radical-positive ions in the order of increasing energy: $4 \mathrm{Cs}$, 1C-I Cs, 1C-II Cs (the nomenclature from [62]) and 1N-I Cs [62] (IV+ Cs [17]). 
Scheme 2. Summary of the major reactions investigated for cation radical- neutral dimer generation of protonated residues (a) abstraction of a $\mathrm{C}_{\text {alpha }}$ proton from the cation radical, (b) abstraction of the C-terminal proton from the cation radical, (c) cation radical dissociation to generate immoium ions and the ${ }^{\bullet} \mathrm{COOH}$ radical. As is typical, full-headed arrows indicate movement of two electrons, while half arrows indicate single electron movement.

(a)

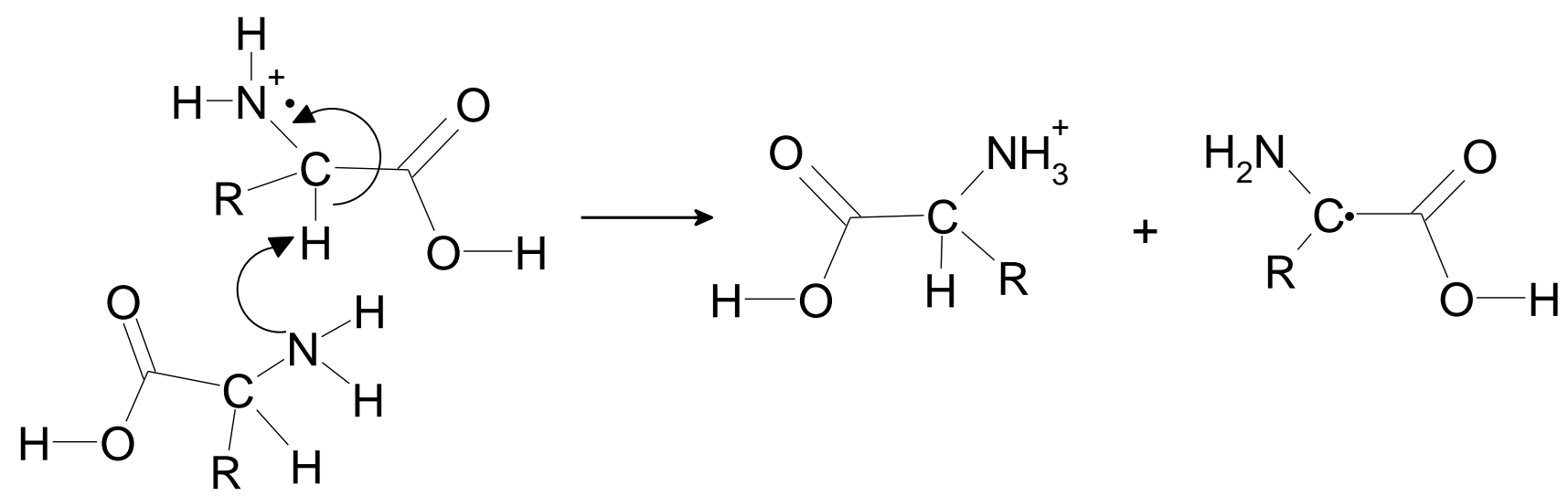

(b)

(c)

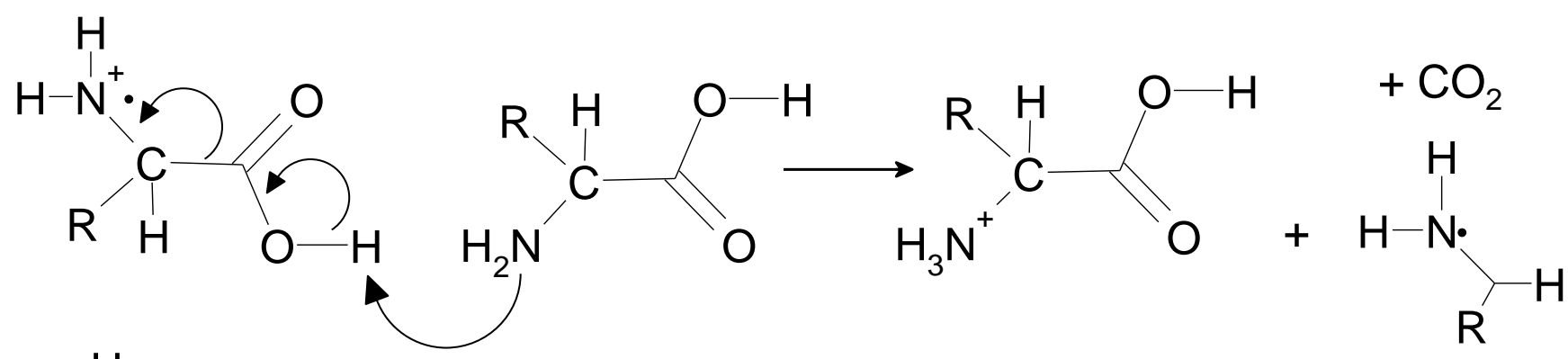<smiles></smiles> 


\section{Table Legends}

Table 1. Summary of Glycine-glycine cation-radical dimer reactions. $\mathrm{RC}=$ reactive configuration, $\mathrm{GM}=$ global minimum dimer. Structures of the dimers, transition structures and product complexes are available in Scheme S1.

\begin{tabular}{|c|c|c|c|c|}
\hline & $\begin{array}{c}\mathrm{B} 3 \mathrm{LYP} / \\
6-311++\mathrm{G}(2 \mathrm{~d}, \mathrm{p}) \\
\Delta \mathrm{H}_{0 \mathrm{~K}}\left(\Delta \mathrm{G}_{298}\right) / \\
\mathrm{kJ} \mathrm{mol}^{-1}\end{array}$ & $\begin{array}{c}\text { Single point MP2/ } \\
\text { 6-311++G(2d,p) } \\
\Delta \mathrm{H}_{0 \mathrm{~K}}\left(\Delta \mathrm{G}_{298}\right) / \\
\mathrm{kJ} \mathrm{mol}^{-1}\end{array}$ & $\begin{array}{c}\text { B3LYP-MP2/ } \\
6-311++\mathrm{G}(2 \mathrm{~d}, \mathrm{p}) \\
\Delta \mathrm{H}_{0 \mathrm{~K}}\left(\Delta \mathrm{G}_{298}\right) / \\
\mathrm{kJ} \mathrm{mol}^{-1}\end{array}$ & $\begin{array}{c}\text { M06-2X/ } \\
\text { 6-311++G(2d,p) } \\
\Delta \mathrm{H}_{0 \mathrm{~K}}\left(\Delta \mathrm{G}_{298}\right) / \\
\mathrm{kJ} \mathrm{mol}^{-1}\end{array}$ \\
\hline Dimer 1 & $17.9(12.7)$ & $29.5(24.2)$ & $23.7(18.5)$ & $22.8(18.7)$ \\
\hline Dimer 2 & $0.0(0.0)$ & $0.0(0.0)$ & $0.0(0.0)$ & $0.2(0.6)$ \\
\hline GM & $0(0)$ & $0(0)$ & $0(0)$ & $0(0)$ \\
\hline $\begin{array}{c}\text { Gly } \mathrm{C}_{\text {alpha }} \mathrm{H}^{+} \\
\text {transfer } \mathrm{TS}\end{array}$ & $22.5(23.1)$ & $14.0(14.6)$ & $18.2(18.9)$ & $23.2(22.2)$ \\
\hline $\begin{array}{l}\text { Gly } \mathrm{C}_{\mathrm{alpha}} \\
\text { product dimer }\end{array}$ & $-113.6(-27.2)$ & $-125.1(-125.6)$ & $-119.4(-119.9)$ & $-100.1(-102.1)$ \\
\hline $\begin{array}{c}{[\mathrm{Gly}+\mathrm{H}]^{+}+} \\
\mathrm{H}_{2} \mathrm{NC}^{\bullet} \mathrm{HCO}_{2} \mathrm{H}\end{array}$ & $3.1(-44.0)$ & $-0.9(-48.0)$ & $1.1(-46.0)$ & $6.0(-43.4)$ \\
\hline $\begin{array}{l}\text { Gly C-terminal } \\
\mathrm{H}^{+} \text {transfer RC }\end{array}$ & $15.3(9.4)$ & $96.1(90.2)$ & $55.7(49.8)$ & $21.1(16.9)$ \\
\hline $\begin{array}{l}\text { Gly C-terminal } \\
\mathrm{H}^{+} \text {transfer TS }\end{array}$ & $24.3(19.4)$ & $60.8(55.8)$ & $42.6(37.6)$ & $33.8(30.0)$ \\
\hline $\begin{array}{l}\text { Gly C-terminal } \\
\mathrm{H}^{+} \text {prod. trimer }\end{array}$ & $-33.8(-50.1)$ & $-45.7(-60.1)$ & $-39.8(-56.1)$ & $-17.7(-24.1)$ \\
\hline $\begin{array}{l}{[\mathrm{Gly}+\mathrm{H}]^{+}+\mathrm{CO}_{2}} \\
\quad+\mathrm{CH}_{2} \mathrm{NH}_{2}^{\bullet}\end{array}$ & $25.2(-61.6)$ & $5.6(-81.2)$ & $15.4(-71.4)$ & $51.6(-39.4)$ \\
\hline
\end{tabular}


Table 2. Summary of Alanine-alanine cation-radical dimer reactions. $\mathrm{RC}=$ reactive configuration, $\mathrm{GM}=$ global minimum dimer. Structures of the dimers, transition structures and product complexes are available in Scheme S2.

\begin{tabular}{|c|c|c|c|c|}
\hline & $\begin{array}{c}\text { B3LYP/ } \\
6-311++\mathrm{G}(2 \mathrm{~d}, \mathrm{p}) \\
\Delta \mathrm{H}_{0 \mathrm{~K}}\left(\Delta \mathrm{G}_{298}\right) / \\
\mathrm{kJ} \mathrm{mol}\end{array}$ & $\begin{array}{c}\text { Single point MP2/ } \\
6-311++\mathrm{G}(2 \mathrm{~d}, \mathrm{p}) \\
\Delta \mathrm{H}_{0 \mathrm{~K}}\left(\Delta \mathrm{G}_{298}\right) / \\
\mathrm{kJ} \mathrm{mol}^{-1}\end{array}$ & $\begin{array}{c}\text { B3LYP-MP2/ } \\
6-311++\mathrm{G}(2 \mathrm{~d}, \mathrm{p}) \\
\Delta \mathrm{H}_{0 \mathrm{~K}}\left(\Delta \mathrm{G}_{298}\right) / \\
\mathrm{kJ} \mathrm{mol}^{-1}\end{array}$ & $\begin{array}{c}\text { M06-2X/ } \\
6-311++\mathrm{G}(2 \mathrm{~d}, \mathrm{p}) \\
\Delta \mathrm{H}_{0 \mathrm{~K}}\left(\Delta \mathrm{G}_{298}\right) / \\
\mathrm{kJ} \mathrm{mol}^{-1}\end{array}$ \\
\hline Dimer 1 & $0.0(0.0)$ & $0.0(0.0)$ & $0.0(0.0)$ & $0.4(0.8)$ \\
\hline Dimer $2 \mathrm{RC}$ & $5.4(3.6)$ & $22.3(20.5)$ & $13.8(12.1)$ & $0.0(0.0)$ \\
\hline $\begin{array}{c}\text { Ala } \mathrm{C}_{\text {alpha }} \mathrm{H}^{+} \\
\text {transfer TS }\end{array}$ & $26.4(25.1)$ & $36.3(35.0)$ & $31.3(30.0)$ & $24.1(24.1)$ \\
\hline $\begin{array}{c}\text { Ala } \mathrm{C}_{\text {alpha }} \\
\text { product dimer }\end{array}$ & $-116.5(-122.2)$ & $5.2(-0.5)$ & $-55.6(-61.3)$ & $-114.7(-117.2)$ \\
\hline $\begin{array}{c}{[\mathrm{Ala}+\mathrm{H}]^{+}+} \\
\mathrm{H}_{2} \mathrm{NCH}_{3} \mathrm{C}^{\bullet} \mathrm{CO}_{2} \mathrm{H}\end{array}$ & $-10.6(-60.2)$ & $-3.8(-53.4)$ & $-7.2(-56.8)$ & $-5.4(-54.9)$ \\
\hline $\begin{array}{l}\text { Ala C-terminal } \\
\mathrm{H}^{+} \text {transfer } \mathrm{RC}\end{array}$ & $16.4(8.3)$ & $91.1(83.0)$ & $53.7(45.6)$ & $15.4(9.7)$ \\
\hline $\begin{array}{l}\text { Ala C-terminal } \\
\mathrm{H}^{+} \text {transfer TS }\end{array}$ & $20.8(15.1)$ & $58.0(52.3)$ & $39.4(33.7)$ & $26.4(23.7)$ \\
\hline $\begin{array}{l}\text { Ala C-terminal } \\
\mathrm{H}^{+} \text {prod. trimer }\end{array}$ & $-46.9(-60.0)$ & $-52.3(-65.5)$ & $-49.6(-62.7)$ & $-29.8(-37.3)$ \\
\hline $\begin{array}{l}{[\mathrm{Ala}+\mathrm{H}]^{+}+\mathrm{CO}_{2}} \\
+\mathrm{CH}_{3} \mathrm{CHNH}_{2}\end{array}$ & $15.2(-77.3)$ & $13.7(-78.9)$ & $14.4(78.1)$ & $47.5(-45.6)$ \\
\hline
\end{tabular}


Table 3. Summary of potential $\mathrm{RHCNH}_{2}{ }^{+}$formation reactions.

\begin{tabular}{|c|c|c|c|c|}
\hline & $\begin{array}{c}\text { B3LYP/ } \\
6-311++\mathrm{G}(2 \mathrm{~d}, \mathrm{p}) \\
\Delta \mathrm{H}_{0 \mathrm{~K}}\left(\Delta \mathrm{G}_{298}\right) / \\
\mathrm{kJ} \mathrm{mol}^{-1}\end{array}$ & $\begin{array}{c}\text { Single point MP2/ } \\
6-311++\mathrm{G}(2 \mathrm{~d}, \mathrm{p}) \\
\Delta \mathrm{H}_{0 \mathrm{~K}}\left(\Delta \mathrm{G}_{298}\right) / \\
\mathrm{kJ} \mathrm{mol}^{-1}\end{array}$ & $\begin{array}{c}\text { B3LYP-MP2/ } \\
6-311++\mathrm{G}(2 \mathrm{~d}, \mathrm{p}) \\
\Delta \mathrm{H}_{0 \mathrm{~K}}\left(\Delta \mathrm{G}_{298}\right) / \\
\mathrm{kJ} \mathrm{mol}^{-1}\end{array}$ & $\begin{array}{c}\mathrm{M} 06-2 \mathrm{X} / \\
6-311++\mathrm{G}(2 \mathrm{~d}, \mathrm{p}) \\
\Delta \mathrm{H}_{0 \mathrm{~K}}\left(\Delta \mathrm{G}_{298}\right) / \\
\mathrm{kJ} \mathrm{mol}^{-1}\end{array}$ \\
\hline $\mathrm{Gly}^{\bullet+}$ & $0.0(0.0)$ & $0.0(0.0)$ & $0.0(0.0)$ & $0.0(0.0)$ \\
\hline $\mathrm{H}_{2} \mathrm{CNH}_{2}{ }^{+}{ }_{-} \mathrm{TS}$ & $45.6(39.1)$ & $12.6(6.1)$ & $29.1(22.6)$ & $43.8(38.1)$ \\
\hline $\begin{array}{c}\mathrm{H}_{2} \mathrm{CNH}_{2}^{+}+ \\
{ }^{\circ} \mathrm{COOH}\end{array}$ & $80.1(35.4)$ & $47.6(2.9)$ & $63.8(19.1)$ & $84.2(39.3)$ \\
\hline $\mathrm{Ala}^{\bullet+}$ & $0.0(0.0)$ & $0.0(0.0)$ & $0.0(0.0)$ & $0.0(0.0)$ \\
\hline $\mathrm{H}_{3} \mathrm{CHCNH}_{2}{ }^{+}{ }_{-} \mathrm{TS}$ & $18.9(15.1)$ & $2.5(-1.3)$ & $10.7(6.9)$ & $22.3(18.0)$ \\
\hline $\begin{array}{c}\mathrm{H}_{3} \mathrm{CHCNH}_{2}^{+}+ \\
{ }^{\circ} \mathrm{COOH}\end{array}$ & $33.5(-13.7)$ & $63.2(16.0)$ & $48.3(1.1)$ & $48.6(1.2)$ \\
\hline$[\mathrm{Gly}+\mathrm{H}]^{+}$ & $3.1(-44.0)$ & $-0.9(-48.0)$ & $1.1(-46.0)$ & $6.0(-43.4)$ \\
\hline TS & $146.8(96.1)$ & $130.8(80.1)$ & $138.8(88.1)$ & $155.5(103.9)$ \\
\hline $\begin{array}{l}\mathrm{H}_{2} \mathrm{CNH}_{2}^{+}+ \\
\mathrm{CO}+\mathrm{H}_{2} \mathrm{O}\end{array}$ & $142.3(60.3)$ & $136.4(10.4)$ & $139.4(13.4)$ & $165.1(37.5)$ \\
\hline$[\mathrm{Ala}+\mathrm{H}]^{+}$ & $-10.6(-60.2)$ & $-3.8(-53.4)$ & $-7.2(-56.8)$ & $-5.4(-54.9)$ \\
\hline TS & $130.3(78.5)$ & $127.7(75.4)$ & $129.0(77.2)$ & $144.2(88.6)$ \\
\hline $\begin{array}{c}\mathrm{H}_{3} \mathrm{CHCNH}_{2}+ \\
\mathrm{CO}+\mathrm{H}_{2} \mathrm{O}\end{array}$ & $75.8(-55.3)$ & $143.3(12.8)$ & $109.6(35.9)$ & $110.4(-21.4)$ \\
\hline
\end{tabular}




\section{References:}

[1] G. Gioumousis, D.P. Stevenson, J. Chem. Phys. 29 (1958) 294.

[2] P.B. Armentrout, J. Anal. At. Spectrom. 19 (2004) 571.

[3] M.S.B. Munson, F.H. Field, J. Am. Chem. Soc. 88 (1966) 2621.

[4] V.L. Tal'roze, A.K. Ljubimova, Doklady Akad. Nauk SSSR, 86 (1952) 909; This paper has been reprinted in J. Mass Spectrom. 33 (1998) 502.

[5] W.T Huntress, Jr., R.F. Pinizzotto, Jr., J. Chem. Phys. 59 (1973) 4742-4756.

[6] F.W. McLafferty, Anal. Chem. 29 (1957) 1782.

[7] G. Junk, H. Svec, J. Am. Chem. Soc. 85 (1963) 839.

[8] H.J. Svec, G.A. Junk, J. Am. Chem. Soc.89 (1967) 790.

[9] V.I. Zaretskii, V.L. Sadovskaya, N.S. Wulfson, V.F. Sizoy, V.G. Merimson, Org. Mass Spectrom. 5 (1971) 1179-1182.

[10] a) K. Bieman, J. Seibl, F. Gapp, J. Am. Chem. Soc. 83 (1961) 3795; b) K. Bieman, J. Seibl, F. Gapp, Biochem. Biophys. Res, Commun, 1 (1959) 307.

[11] NIST Chemistry WebBook, http://webbook.nist.gov.

[12] J.R. Majer, B.I. Al-Ali, A.S.P. Azzouz, Org. Mass Spectrom, 16 (1981) 147.

[13] S. Simon, M. Sodupe, and J. Bertran, J. Phys. Chem. 106 (2002) 5697-5702.

[14] H.-F. Lu, F.-Y. Li, S.H. Lin J. Phys. Chem. A 108 (2004) 9233-9243.

[15] S. Simon, A. Gil, M. Sodupe, and J. Bertran, J. Mol. Struct. (Theochem) 727 (2005) 191-197.

[16] J. Tamuliene, L.G. Romanova, V.S. Vukstich, and A.V. Snegursky, Lithuanian J. Phys. 53 (2013) 195209.

[17] L. Rodriguez-Santiago, M. Sodupe, A. Oliva, J. Bertran, J. Phys. Chem. A 104, (2000) 1256-1261.

[18] G. Y. Lee, Bull. Korean Chem. Soc. 33 (2012) 1561-1565.

[19] R.A.J. O’Hair, P. S. Broughton, M. L. Styles, B.T. Frink, C.M. Hadad, J. AM. Soc. Mass Spectrom., (11), 2000, 687-696,

[20] I. Csonka, B. Paizs, S. Suhai, Journal of Mass Spectrometry 39 (2004) 1025-1035

[21] I. Ipolyi, P. Cicman, S. Denifl, V. Matejcik, P. Mach, J. Urban, P. Scheier, T.D. Mark, S. Matejcik, Int. J. Mass Spectrom. 252 (2006) 228-233.

[22] V.S. Vukstich, A.I. Imre, L.G. Romanova, A.V. Snegursky, J. Phys. B: Atom Mol. Opt. Phys., 43 (2010) $185208(1-6)$. 
[23] J. Tamuliene, L.G. Romanova, V.S. Vukstich, A.V. Snegursky, Nuclear Instruments \& Methods in Physics Research Section B-Beam Interactions with Materials and Atoms 279 (2012) 128-134.

[24] T.P Debies, J.W. Rabalais, J. Electron Spectrosc. Relat. Phenom. 3 (1974) 315.

[25] a) P.H. Cannington, N.S. Ham, J. Electron Spectrosc. Relat. Phenom. 32 (1983) 139; b) P.H. Cannington, N.S. Ham, J. Electron Spectrosc. Relat. Phenom. 32 (1979) 79

[26] F.I. Vilesov, Vestn. Leningr. Univ. 15 (1966) 40.

[27] a) L. Klasinc, J. Electron Spectrosc. Relat. Phenom. 8 (1976) 161; b) L. Klasinc, Int. J. Quantum Chem.: Quantum Biology Symposium, 5 (1978) 373-380.

[28] Y. Yamakita, K. Ohno, J. Phys. Chem. A 113 (2009) 10779-10786.

[29] H.-W. Jochims, M. Schwell, J.-L. Chotin, M. Clemino, F. Dulieu, H. Baumgärtel, S. Leach, Chem. Phys. 298 (2004) 279.

[30] V.G. Voinov, Y.V. Vasil'ev, J. Morré, D.F. Barofsky, M.L. Deinzer, M. Gonin, T.F. Egan, K. Führer, Anal. Chem. 75 (2003) 3001-3009.

[31] V.G. Voinov, Y.V. Vasil'ev, H. Ji, B. Figard, J. Morré, T.F. Egan, D.F. Barofsky, M.L. Deinzer, Anal. Chem. 10 (2004) 2951-2957.

[32] A. Stamatovic, G.J. Schulz, Rev. Sci. Instrum. 41 (1970) 423-427.

[33] Y.V. Vasil'ev, V.G. Voinov, D.F. Barofsky, M.L. Deinzer, Int. J. Mass Spectrom. 277 (2008) 142-150.

[34] Y.V. Vasil'ev, B.J. Figard, J. Morré, M.L. Deinzer, J. Chem. Phys. 131 (2009) 044317(1-11).

[35] M. J. Frisch, G. W. Trucks, H. B. Schlegel, G. E. Scuseria, M. A. Robb, J. R. Cheeseman, G. Scalmani, V. Barone, B. Mennucci, G. A. Petersson, H. Nakatsuji, M. Caricato, X. Li, H. P. Hratchian, A. F. Izmaylov, J. Bloino, G. Zheng, J. L. Sonnenberg, M. Hada, M. Ehara, K. Toyota, R. Fukuda, J. Hasegawa, M. Ishida, T. Nakajima, Y. Honda, O. Kitao, H. Nakai, T. Vreven, J. A. Montgomery, Jr., J. E. Peralta, F. Ogliaro, M. Bearpark, J. J. Heyd, E. Brothers, K. N. Kudin, V. N. Staroverov, R. Kobayashi, J. Normand, K. Raghavachari, A. Rendell, J. C. Burant, S. S. Iyengar, J. Tomasi, M. Cossi, N. Rega, J. M. Millam, M. Klene, J. E. Knox, J. B. Cross, V. Bakken, C. Adamo, J. Jaramillo, R. Gomperts, R. E. Stratmann, O. Yazyev, A. J. Austin, R. Cammi, C. Pomelli, J. W. Ochterski, R. L. Martin, K. Morokuma, V. G. Zakrzewski, G. A. Voth, P. Salvador, J. J. Dannenberg, S. Dapprich, A. D. Daniels, O. Farkas, J. B. Foresman, J. V. Ortiz, J. Cioslowski, and D. J. Fox, Gaussian, Inc., Wallingford CT, 2009.

[36] A.D. Becke, Phys. Rev. A 38 (1988) 3098-3100; C. Lee, W. Yang, R.G. Parr, Phys. Rev. B 37 (1988) 785-789; A.D. Becke, J. Chem. Phys. 98 (1993) 5648-5652.

[37] Y.Zhao, D.G. Truhlar, Theor. Chem. Account 120 (2008) 215-241. 
[38] C. Møller, M.S. Plesset, Phys. Rev. 46 (1934), 618.

[39] F. Tureček, J. Phys. Chem. A, 102 (1998) 4703.

[40] T. Beyer, D.R. Swinehart, ACM Commun. 16 (1973) 379

[41] D. Muigg, G. Denifl, A. Stamatovic, O. Echt, T.D. Märk, Chem. Phys., 239 (1998) 409.

[42] A.V. Pogulay, R.R. Abzalimov, S.K. Nasibullaev, A.S. Lobach, T. Drewello, Y.V. Vasil'ev, Int. J. Mass Spectrom. 233 (2004) 165.

[43] M.A. Slifkin, A.C. Allison, Nature 215 (1967) 949.

[44] H. Farrokhpour, F. Fathi, and A. N. De Brito, J. Phys. Chem. A 116 (2012) 7004-7015.

[45] I. Powis, E. E. Rennie, U. Hergenhahn, O. Kugeler, and R. Bussy-Socrate, J. Phys. Chem. A 107 (2003) 25-34.

[46] R. R. T. Marinho, A. F. Lago, M. G. P. Homem, L. H. Coutinho, G. G. B. de Souza, and A. N. de Brito, Chem. Phys. 324 (2006) 420-424.

[47] Y.Zheng, J.J. Neville, C.E. Brion, Science, 270 (1995) 786-788.

[48] J.J. Neville, Y. Zheng, C.E. Brion, J. Am. Chem. Soc. 118 (1996) 10533-10544.

[49] D. Gross, G. Grodsky, J. Am. Chem. Soc. 77 (1955) 1678-1680.

[50] V.S. Vukstich, A.I. Imre, A.V. Snegursky, Tech. Phys. Letters, 35 (2009) 1071-1073.

[51] M. Nyberg, J. Hasselström, O. Karis, N. Wassdahl, M. Weinelt, A. Nilsson, L.G.M. Pettersson, J. Chem. Phys. 112 (2000) 5420-5427.

[52] A. Iakovidis, N. Hadjiliadis, I.S. Butler, Spectrochimica Acta, 47A (1991) 1567-1574.

[53] J. Williams, S. Haq, R. Raval, Surface Science, 368 (1996) 303-309.

[54] Y.V. Vasil'ev, B.J. Figard, V.G. Voinov, D.F. Barofsky, M.L. Deinzer, J. Am. Chem. Soc., 128 (2006) 5506-5515.

[55] H.J. Svec, D.D. Clyde, J. Chem. Eng. Data 10 (1965) 151.

[56] C.G. de Kruif, J. Voogd, J.C.A. Offringa, J. Chem. Thermodynamics 11 (1979) 651.

[57] F. Huissken, O. Werhahn, A.Yu. Ivanov, S.A. Krasnokutski, J. Chem. Phys. 111 (1999) 2978.

[58] J. Chocholoušová, J. Vacek, F. Huisken, O. Werhahn, P. Hobza, J. Phys. Chem. A 106 (2002) 11540.

[59] S. Denifl, I. Mähr, F. F. da Silva, F. Zappa. T.D. Märk, P. Scheier, Eur. Phys. J. D 51 (2009) 73.

[60] B. Bellina, D.J. Merthe, V.V. Kresin, J. Chem. Phys.142 (2015)114306(1-5).

[61] Y. Ren, R. Moro, V.V. Kresin, Eur. Phys. J. D 43 (2007) 109.

[62] D. Yu, A. Rauk, D.A. Armstrong, J. Am. Chem. Soc. 117 (1995) 1789-1796.

[63] K.N. Sutherland, P.C. Mineau, G. Orlova, J. Phys. Chem. 111 (2007) 7906-7914. 
[64] F. Turecek, S. Panja, J.A. Wyer, A. Ehlerding, H. Zettergren, S.B. Nielsen, P. Hvelplund, B. Bythell, B. Paizs,. J. Am. Chem. Soc. 131 (2009) 16472.

[65] R. Pepin, K.J. Laszlo, B. Peng, A. Marek, M.F. Bush, F. Turecek, J. Phys. Chem. A, 118 (2014) 308.

[66] B.J. Bythell, J. Phys. Chem. A 117 (2013) 1189.

[67] B.J. Bythell, J. Phys. Chem. A 118 (2014) 10797.

[68] B.N. Moore, T. Ly, R.R. Julian, J. Am. Chem. Soc., 133 (2011) 6997.

[69] F. Tureček, R.R. Julian, Chem. Rev., 113 (2013) 6691. 


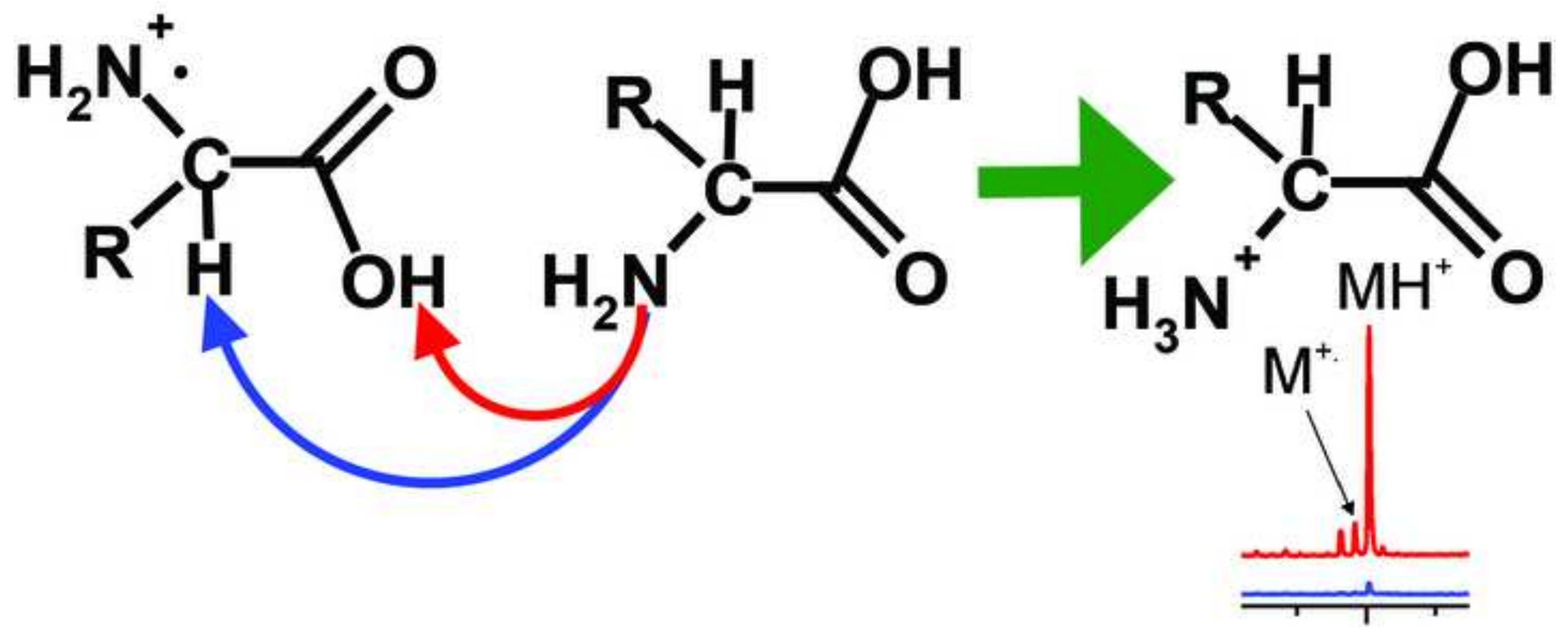

